\title{
Distinct Embryonic and Adult Fates of Multipotent Myogenic Progenitors Isolated from Skeletal Muscle and Bone Marrow
}

\author{
Zhuqing Qu-Petersen ${ }^{1}$, Jesper L. Andersen ${ }^{2}$, Shi Zhou ${ }^{3}$ \\ ${ }^{1}$ The Copenhagen Muscle Research Center, National University Hospital, Copenhagen, Denmark \\ ${ }^{2}$ Institute of Sports Medicine and Center for Healthy Aging, University of Copenhagen, Bispebjerg Hospital, Copenhagen, Denmark \\ ${ }^{3}$ School of Health and Human Sciences, Southern Cross University, Lismore, Australia
}

Email address:

zhuqing.qu.petersen@rh.regionh.dk (Zhuqing Qu-Petersen)

\section{To cite this article:}

Zhuqing Qu-Petersen, Jesper L. Andersen, Shi Zhou. Distinct Embryonic and Adult Fates of Multipotent Myogenic Progenitors Isolated from Skeletal Muscle and Bone Marrow. Cell Biology. Vol. 3, No. 4, 2015, pp. 58-73. doi: 10.11648/j.cb.20150304.12

\begin{abstract}
Identification of multipotent progenitors has been difficult due to their rarity in adults. Here, we report a novel type of neuroepithelial myogenic progenitor that can be isolated from adult murine skeletal muscle. In culture, these progenitors generated radial glia-like cells that initiated mosaic myotubes, and subsequently developed into embryonic/fetallike myoblasts capable of robust myofiber formation. These cells could also differentiate into neuronal lineage. By contrast, progenitors from bone marrow produced progenies more uniformly of an adult myoblast lineage. When grafted into dystrophic muscles of mdx mice, the muscle- and marrow-derived cells restored dystrophin expression; however, fetal-like myogenesis towards a defective adult fate was demonstrated in the muscle-derived cells. This impaired regenerative capacity resembled Duchenne muscular dystrophy patients, suggesting a potential connection between the neuroepithelial myogenic progenitor and the etiology of this myopathy. The distinct fates of the two types of progenitors imply their different roles in muscle regeneration and pathogenesis.
\end{abstract}

Keywords: Neuroepithelial Myogenic Progenitors, Bone Marrow Myogenic Cells, Neural Differentiation, Myogenesis, Cell Transplantation, Muscular Dystrophy

\section{Introduction}

Isolation and identification of purified multipotent progenitor/stem cells from postnatal tissues have become a major focus of basic and clinical investigations [1, 2]. These cells can provide a range of tissue-specific progenitors for repair of damaged tissues or modeling human disease [3, 4]. Over the past decade, different tissue-associated progenitor cells have been isolated, and tested for muscle regeneration, especially in the animal models of Duchenne muscular dystrophy (DMD) [5-11]. DMD is the most common and severe form of congenital muscle disease, in which the absence of dystrophin in the membrane of myofibers results in muscle fiber necrosis and progressive muscle weakness [12]. Stem cell therapy may provide the opportunity to restore dystrophin expression and replace the damaged muscle tissue [13, 14]. To date, the efficiency of initial grafting myoblasts or muscle satellite cells is too low to meet therapeutic objectives, and the recent advances in the strategies have encountered different challenges [13, 14].

Adult bone marrow has been considered as accessible sources for isolation of multipotent myogenic progenitors. A side population (SP cells) sorted by their ability to efflux the Hoechst dye and mesenchymal stromal cells (MSCs) separated as adherent cells in culture or by lineage markers, have been tested for muscle differentiation $[5,7,8,11]$. However, poor engraftments have resulted from transplantation of bone marrow-derived cells, including SP cells and MSCs into dystrophic mice [5, 8, 15]. More immature subpopulations of myogenic progenitors sorted by pre-defined cell surface markers from skeletal muscle are able to contribute to the satellite cell pool and give improved engraftments in dystrophin-deficient $m d x$ mice [16-18]. Different populations of myogenic cells have also been derived from vascular progenitor cells [9], adipose-derived progenitors [10], genetically modified mesenchymal stem cells [19], and embryonic stem cells [20]. While the efficiency of engraftments is improving, muscle function has 
been limited, and variable [21, 22], and tumorigenesis has been reported in studies [19, 20]. These outcomes raise critical issues about the heterogeneity of the original progenitor cells transplanted and the physiological role of multipotent progenitors in muscle regeneration.

Most of the investigations have focused on the development of adult myogenic progenitor/stem cells for use in cell replacement therapy. Indirect evidence from human pathology, however, suggests the presence of more immature progenitors in postnatal tissues. For example, despite the origin of single cells, both neuroblastoma and rhabdomyosarcoma contain embryonic-like tissues with muscle and neural cell phenotypes [23]. This suggests that a rare number of primitive myogenic cells may exist in postnatal tissues, and function differently from tissue-specific progenitor/stem cells. Identification of these primitive progenitors is crucial when considering the proposed therapeutic roles of multipotent cells in regenerative medicine. In addition, understanding of the basic biology of the immature progenitors may provide insights into the cellular origin of human diseases [3, 4, 24]. Because of the low frequency of these cells in adults, isolation and identification of purified primitive cells in a given tissue have been difficult.

In the present study, we aimed to isolate purified primary colonies of multipotent progenitors with myogenic potential from adult skeletal muscle. To test whether myogenic progenitors could be obtained from other sources, we also isolated primary colonies from bone marrow by similar approaches. We report in this paper the identification and characterization of the most primitive cells from normal murine skeletal muscle, termed neuroepithelial myogenic progenitors (NEMPs), by comparing their marker profiles, myogenic/neurogenic potential, and transplantation capacity with myogenic cells isolated from bone marrow (BMMCs).

\section{Experimental Procedures}

\subsection{Cell Isolation}

NEMPs were isolated from the hindlimb muscle of normal C57BL/6 mice (five weeks old) by clonal isolation. A subset of suspension cells was first collected from primary muscle cultures at isolation day 5, using a modified preplate technique reported previously $[6,25,26]$. The suspension cells were then seeded at a clonal density $\left(15-30\right.$ cells $\left./ \mathrm{cm}^{2}\right)$ in culture wells, and developed primary colonies in two weeks. NEMPs were originally from three primary colonies, presumably three primitive NEMP cells. The frequency of the primary NEMP colonies is one in $130 \mathrm{mg}$ hindlimb muscle (from five independent isolations). Two primary clonal populations of NEMP-c1 and NEMP-c2 were established by two times of cloning to confirm single cell nature of the NEMP colonies. BMMCs were isolated from the femurs of normal mice (seven weeks old) by similar technique of preplate and clonal isolation used for NEMP cells, except that the marrow cells were treated with the supernatant of muscle extract before progressing preplate. We filtered the supernatant and checked no cells in it. The frequency of BMMC colony is approximately one per $10^{5}$ $10^{6}$ marrow cells. All the cell populations were of female origin except the NEMP-c1, which was deliberately derived from male mice. The detailed information for isolation can be found in supplementary information.

\subsection{Cell Growth}

Each primary clone/colony contained 50-100 cells, and thus expansion of these cells was carried out and was set as passage $1\left(\mathrm{P}_{1}\right)$. The NEMP populations tended to differentiate and fuse rapidly in the early cultures. To establish adequate less differentiated cells, the expansion of NEMPs and BMMCs at $\mathrm{P}_{1-5}$ was carried out in the growth medium $(20 \%$ serum) at a density of $0.5-2.5 \times 10^{3}$ cells $/ \mathrm{cm}^{2}$. The medium was changed daily. The BMMCs could be expanded at a higher cell density without fusing. The passages at this stage are defined as the times when trypsin was used to detach the cells, starting from the initial expansion of the primary colonies. From $\mathrm{P}_{6}$, the cells were seeded at a cell density of $1.5 \times 10^{3}$ cells $/ \mathrm{cm}^{2}$ and passaged when the culture reached $\sim 7.5 \times 10^{3}$ cells $/ \mathrm{cm}^{2}$ (NEMPs) and $\sim 1.5 \times 10^{4}$ cells $/ \mathrm{cm}^{2}$ (BMMCs). The medium was changed every 2 days. The number of cells per $\mathrm{cm}^{2}$ was counted at daily intervals for calculating the population doublings, and two culture samples were used for each cell type from $\mathrm{P}_{6}$.

\subsection{In Vitro Myofiber Formation}

To investigate early spontaneous differentiation, the NEMPs and BMMCs at $\mathrm{P}_{3-5}$ were seeded in 12-well plates at a density of $2.5-5 \times 10^{3}$ cells $/ \mathrm{cm}^{2}$. After culturing in the growth medium for 5 days, SMMts/myotubes developed and the cells were fixed with cold methanol for immunocytochemistry and myofiber formation. To examine induced myofiber formation, NEMPs and BMMCs at $\mathrm{P}_{8-12}$ and $\mathrm{P}_{16-20}$ were seeded in 6-well plates and grown to a density of $1.5-2 \times 10^{4}$ cells $/ \mathrm{cm}^{2}$. The growth medium was then replaced with differentiation medium ( $2 \%$ horse serum) for 5 days. The cells were fixed and the number of nuclei in myotubes and the total number of nuclei were scored in five random fields $(\times 100)$ per well. Quantitative analysis of differentiation kinetics was performed in five or six individual trials by measuring the fusion index, which was expressed as the percentage of nuclei incorporated into myotubes [27].

\subsection{Cell Transplantation}

We grafted BMMCs, NEMPs and NEMP-c1 $\left(\mathrm{P}_{8-12}\right)$ into the gastrocnemius medialis of dystrophin-deficient $m d x$ mice (C57BL/10ScSn-Dmd ${ }^{m d x} / \mathrm{J}, \quad 6-14$ weeks old) as single injection. For each muscle, $1.5 \times 10^{5}$ or $3 \times 10^{5}$ cells, suspended in $15 \mu \mathrm{l}$ of HBSS (Life Technologies), were used. The total number of cells grafted was varied due to the difficulty in expansion of NEMP myogenic cells. The mice were sacrificed at 14 days or 40-50 days post-grafting and 
the entire gastrocnemius muscles were frozen for analysis. BMMCs $\left(5 \times 10^{4}\right)$ were also injected into the irradiated tibialis anterior muscles of $m d x \mathrm{nu} / \mathrm{nu}$ mice and the injected muscles were assessed 35 days after grafting [16].

\subsection{Immunohistochemistry and Histochemistry}

\subsubsection{Dystrophin Immunostaining}

Serial cryosections $(10 \mu \mathrm{m})$ were collected throughout the gastrocnemius muscles. The sections were fixed in acetone for $5 \mathrm{~min}$ at $-20^{\circ} \mathrm{C}$, and blocked in $5 \%$ serum or $1 \%$ BSA for $30 \mathrm{~min}$ at room temperature. For dystrophin staining, sections were incubated with rabbit antidystrophin antibody (1:1, Neo Markers) for $30 \mathrm{~min}$ and Alexa Fluor 594 (1:500, Life Technologies) for $30 \mathrm{~min}$, and counterstained with Hoechst 33342 (Sigma-Aldrich). The cross sections with the highest number of dystrophin ${ }^{+}$fibers were counted in the grafted gastrocnemius medialis. The percentage of CNFs, and the diameter of myofibers were measured from an average of 600 dystrophin $^{+}$fibers (172-2141) in between five and 10 sections for each injected muscle. The diameter of dystrophin ${ }^{+}$fibers was measured from the short diameter of polygonal myofibers (the relative diameter). For the non-grafted areas, five sections of the gastrocnemius lateralis were counted for the average of dystrophin ${ }^{+}$fibers, and an average of 392 and 309 myofibers from three randomly chosen areas were measured for the percentage of CNFs and the diameter of myofibers. To evaluate dystrophin ${ }^{-}$fibers in the late grafts, the gastrocnemius medialis with large numbers of small dystrophin $^{-}$fibers were used. The percentage of dystrophin $^{-}$fibers with peripheral or central nuclei was measured by differential interference contrast (DIC) images merged with dystrophin and Hoechst staining, from an average of 602 dystrophin $^{-}$fibers (465-752) in between three and five sections for each grafted muscle.

\subsubsection{Developmental Myosin Heavy Chain (Dev-MyHC) and Dystrophin Double Staining}

The sections were incubated with anti-dev-MyHC (1:20, Vector Laboratories) for $90 \mathrm{~min}$, and the next steps were performed according to the instructions of M.O.M. ${ }^{\mathrm{TM}}$ kit manufacturer (Vector Laboratories). The sections were then stained with anti-dystrophin as described above.

\subsubsection{Pax7 and Dystrophin Double Staining}

The sections were incubated with mouse anti-Pax7 (1:50, R\&D Systems) for $2 \mathrm{~h}$ and Alex Fluor 594 goat anti-mouse IgG1 (1:500, Life Technologies) for $1 \mathrm{~h}$. The sections were then stained with anti-dystrophin (1:1, Neo Markers) followed by Alexa Fluor 488 donkey anti-rabbit IgG (1:500, Life Technologies), and counterstained with Hoechst. The number of $\operatorname{Pax}^{+}$cells was counted in 15-20 fields $(\times 200)$ of both grafted (dystrophin ${ }^{+}$fibers) and non-grafted areas (adjacent dystrophin- fibers), in three to six sections of each injected muscle.

\subsubsection{Pax7 and Laminin Double Staining}

Staining was performed as described above except that anti-dystrophin was replaced by anti-laminin (1:100, SigmaAldrich).

\subsubsection{MyoD and Dystrophin Double Staining}

Staining was performed as described for Pax7 and dystrophin double staining except that anti-Pax7 was replaced by anti-MyoD (1:80, BD Biosciences).

\subsubsection{Hematoxylin \& Eosin Stain}

Staining was performed according to the manufacturer's instructions (Sigma-Aldrich).

\subsection{Statistics}

Data were presented as mean \pm SEM. Student's $t$-test was used to compare differences between NEMPs and BMMCs in expression of the transcripts, the myofiber formation, the population doubling time, and the transplantation capacity. An alpha level of $P \leq 0.05$ was set for statistical significance.
Additional
methods
(Neural
Differentiation, Immunocytochemistry, Flow Cytometry, SDS-PAGE and Western Blotting, Real-Time RT-PCR, NEMP Clone Isolation and In Situ Hybridization) can be found in the supplementary information of the paper.

\section{Results}

\subsection{Cell Populations and Marker Profiles}

NEMPs and BMMCs were used in the main analysis of the study. NEMP-c1 and NEMP-c2 were also used in separate experiments due to the small number of primitive NEMP cells. In the growth medium, NEMPs and BMMCs could be propagated for more than 20 passages (Fig. 1A), which is equivalent to 48 (for NEMPs) and 62 population doublings (for BMMCs). Based on our primary focus on the primitive progenitors and their differentiation, the NEMPs at passages 3-6 $\left(\mathrm{P}_{3-6}\right), \mathrm{P}_{8-12}$, and $\mathrm{P}_{16-20}$, and their BMMC counterparts were analyzed.

We first evaluated the marker profiles in activated primitive $\left(\mathrm{P}_{3}\right)$ and more differentiated NEMPs and BMMCs $\left(\mathrm{P}_{11}\right)$ by quantitative RT-PCR (Fig. 1B). In NEMP- $\mathrm{P}_{3}$, neural progenitor marker nestin [28] was 2.12-fold higher $(\mathrm{P}<0.05)$ than in $\mathrm{P}_{11}$, which fits high expression of nestin in neural progenitors and low expression in their differentiated cells. In BMMCs, Nestin was low in $\mathrm{P}_{3}$ and slightly higher in $\mathrm{P}_{11}$ (1.38-fold, $\mathrm{P}>0.05)$. Since $>85 \%$ of BMMC cells in $\mathrm{P}_{11}$ were committed to a myogenic lineage (see below), the increased nestin expression is unlikely related to a neural progenitor phenotype. In $\mathrm{P}_{3}$, myogenic regulatory factors (MRFs) MyoD and myogenin were higher in NEMPs than in BMMCs, suggesting NEMP's high potential for myogenic differentiation. In $\mathrm{P}_{11}, M y o D$ transcript remained at a higher level in NEMPs than in BMMCs. By contrast, Myf5 transcript, one of the MRFs, was lower in $\mathrm{P}_{3}$ and upregulated in $\mathrm{P}_{11}$ of both NEMPs and BMMCs. Embryonic muscle progenitor marker Pax3 [29-31] was observed in NEMP- $\mathrm{P}_{3}$ and rapidly up-regulated in $\mathrm{P}_{11}$. For BMMCs, although $\operatorname{Pax} 3$ became detectable in all the samples of $\mathrm{P}_{11}$, its 
expression was 6-fold higher in NEMPs. In $\mathrm{P}_{3}$, satellite cell marker $\operatorname{Pax} 7$ was detected in two of four samples of NEMPs and BMMCs. Embryonic stem cell marker Oct-4 and PNS glial marker Sox10 were not detected in NEMPs and BMMCs, although Sox10 was observed in an independent NEMP population (not shown). The data indicate (Fig. 1C) that activated NEMPs expressed high levels of markers for neural progenitor and muscle lineage $\left(\mathrm{P}_{3}\right.$, nestin $^{\text {hi }} M_{y o D^{\text {hi }}}$ myogenin $\left.^{\text {hi }}\right)$ and differentiated into embryoniclike myogenic cells $\left(\mathrm{P}_{11}, M y o D^{\mathrm{hi}} M y f 5^{\mathrm{hi}}\right.$ Pax $\left.3^{\mathrm{hi}}\right)$, but BMMCs displayed more homogeneous myogenic marker profiles in $\mathrm{P}_{3}$ and $\mathrm{P}_{11}$.
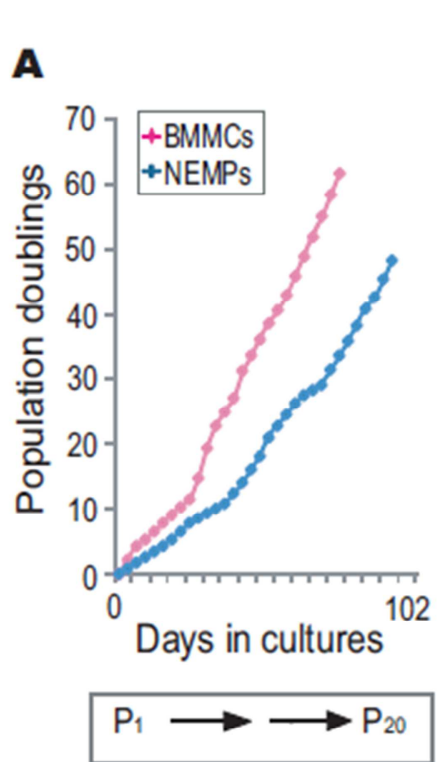

$\mathrm{P}_{3} \quad$ Activated primitive cells P11 More differentiatied œlls
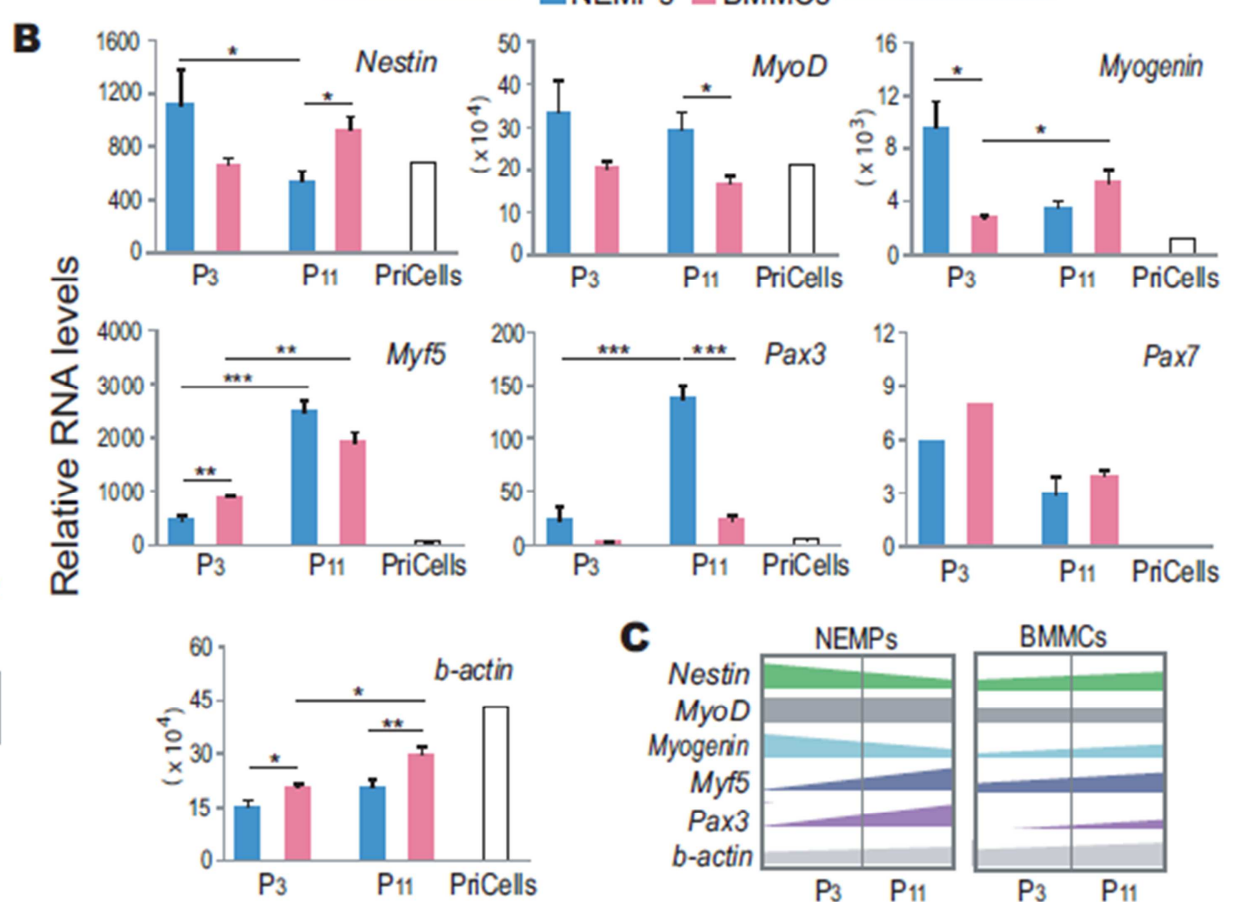
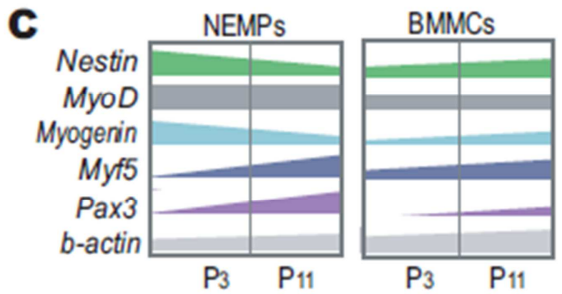

Figure 1. Growth Property and Early Lineage Identification by Quantitative RT-PCR.

(A) Growth curves of population doublings versus days in subcultures, started from passages 1-20 $\left(\mathrm{P}_{1-20}\right)$.

(B) Real-time RT-PCR of activated NEMPs $\left(\mathrm{P}_{3}\right)$ and their differentiated progeny $\left(\mathrm{P}_{11}\right)$, compared with BMMCs. Values represent mean \pm SEM $\left(\mathrm{n}=4\right.$ for $\mathrm{P}_{3}, \mathrm{n}$ $=6$ for $\mathrm{P}_{11}, * P<0.05$, ** $\left.P<0.01, * * * P<0.001\right)$. PriCells: Primary muscle cells cultured for five days.

(C) Diagram summarizes different levels of transcripts from Figure $1 \mathrm{~B}$, showing nestin ${ }^{\text {hi }} M y o D^{\text {hi }}$ myogenin $^{\text {hi }}$ and $P a x 3$ in NEMP-P 3 and $M y o D^{\text {hi }} M y f 5^{\text {hi }} P a x 3^{\text {hi }}$ in NEMP- $\mathrm{P}_{11}$, but more uniform transcripts in BMMC- $\mathrm{P}_{3}$ and $-\mathrm{P}_{11}$.

Analysis of additional neural progenitor markers by immunocytochemistry revealed that Musashi 1 (Msi1) and glial fibrillary acidic protein (GFAP) were expressed in $98.7 \%$ and $50.4 \%$ of NEMPs $\left(\mathrm{P}_{5-6}\right)$, but were weakly $(84.9 \%)$ or negatively detected in BMMCs (Fig. 2A). Thus, the majority of $\mathrm{MyoD}^{+}$cells $(19.3 \%)$ in NEMPs co-expressed Msi1 at this stage; in contrast, $37.4 \%$ of BMMCs coexpressed MyoD and low levels of Msil (Fig. 2A). In $\mathrm{P}_{8-12}$, $41.6 \%$ of NEMPs expressed MyoD, but only $9.6 \%$ of $\mathrm{MyoD}^{+}$ cells were detected in $\mathrm{P}_{16-20}$ (Fig. 2B). However, 85.4-95.3\% of BMMCs expressed MyoD and Pax7 in $\mathrm{P}_{8-12}$, and maintained at $42.7-57.8 \%$ in $\mathrm{P}_{16-20}$. By flow cytometry, both populations expressed stem cell markers ABCG2 and Sca-1, but CD34 (27.9\%) and CD24 (60.1\%) were detected in BMMCs (Fig. 2B), which are markers for hematopoietic progenitors, and also are expressed in non-blood cells [32]. The results further supported that early NEMPs exhibited phenotypes for neural/muscle progenitors (nestin ${ }^{\text {hi }} \mathrm{Msi1}^{\mathrm{hi}} \mathrm{GFAP}^{+} M y o D^{\mathrm{hi}}$ ). By contrast, while the marker profiles suggest the multipotency of BMMCs, the cells could produce adult-like myoblasts $\left(\mathrm{MyoD}^{+} \mathrm{Pax} 7^{+}\right)$for more than 50 population doublings.

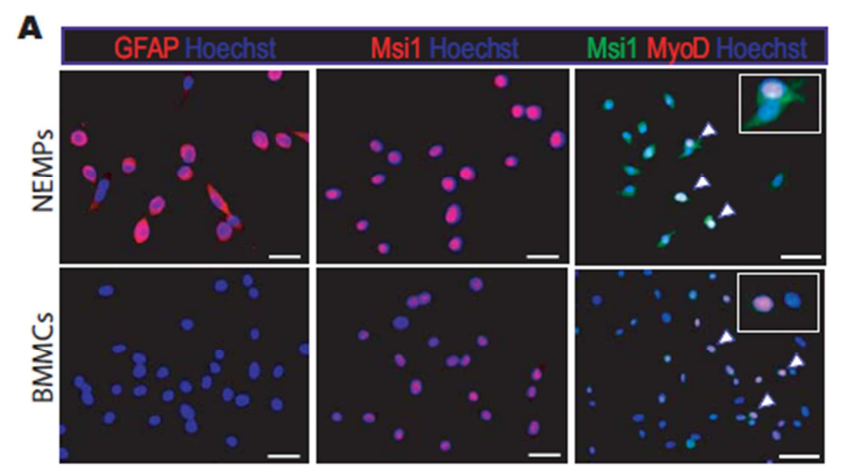

\begin{tabular}{|l|ccccccc|}
\hline Markers & GFAP & Msi1 & Wnt-1 & Pax3 & MyoD & Nanog \\
\hline NEMPs (P5/6) & ++ & ++++ & ++++ & + & + & - \\
BMMCs (P5/6) & - & $(+++)$ & $(+++)$ & - & ++ & - \\
\hline
\end{tabular}


B

\begin{tabular}{|l|cc|ll|}
\hline \multirow{2}{*}{ Markers } & \multicolumn{2}{|c|}{ NEMPs } & \multicolumn{2}{c|}{ BMMCs } \\
\cline { 2 - 5 } & P8-12 & P16-20 & P8-12 & P16-20 \\
\hline * Desmin & ++++ & + & ++++ & +++ \\
MyoD & ++ & + & +++ & ++ \\
Pax7 & $(++)$ & - & ++++ & +++ \\
Myogenin & - & - & + & - \\
\hline ** ABCG2 & +++ & ND & ++ & ND \\
Sca-1 & + & ++ & + & ++ \\
CD133 & - & - & - & - \\
CD34 & - & - & ++ & - \\
CD24 & - & ND & +++ & ++ \\
\hline
\end{tabular}

Figure 2. Analysis of Marker Profiles by Immunocytochemistry and Flow Cytometry.

(A) Immunostaining of neural progenitor markers shows positive/high expression of GFAP and Msi1 in NEMP- $\mathrm{P}_{6}$, and negative/low expression of these markers in BMMCs. Arrowheads indicate $\mathrm{MyoD}^{+} / \mathrm{Msi}^{\text {hi }}$ cells in NEMPs, and $\mathrm{MyoD}^{+} / \mathrm{Msi1}^{\text {low }}$ cells in BMMCs. Note that Msi1 was localized in nuclei and cytoplasm.

(B) Immunocytochemistry $(*)$ and flow cytometry $(* *)$ of $\mathrm{P}_{8-12}$ and $\mathrm{P}_{16-20}$. The percentage of positive cells in (A) and (B) was:,$-<5 \% ;+, 5-25 \%$; ++, $26-50 \%$; +++, $51-90 \%$; ++++, $>90 \%$. The values in parentheses indicate the weakly stained cells.

Scale bars, $20 \mu \mathrm{m}$ in A.

\subsection{NEMPs, but Not BMMCs, Underwent Initial Neuromuscular Differentiation and Produced Embryonic-Like Myotubes in Culture}

A distinct feature of the early NEMPs was their spontaneous differentiation into spindle-shaped mosaic myotubes (SMMts), some of which resulted from radial glialike cells and myoblasts (Fig. 3A). The initial generation of SMMts did not require common differentiation conditions ( $2 \%$ serum), and is agreement with high expression of $M y o D$ and myogenin transcripts of the cells. Immunocytochemistry revealed that SMMts expressed glial marker S-100, neuronspecific beta-III tubulin, and early myogenic cell marker desmin (Fig. 3A). They were also positive for radial glial marker GFAP, and a few of them $(0.7 \%)$ became organized into a tissue pattern (Fig. 3B). Approximately half of the SMMts expressed neural markers beta-III tubulin, GFAP, and S-100, and $93 \%$ of them expressed desmin, supporting their myotube phenotype (Fig. 3C). In comparison, the majority of BMMCs did not fuse in the growth medium (Fig. 3D), although occasional cells expressed S-100 (4\%) and beta-III tubulin (3\%). One of the characteristics of BMMCs was their ability to form desmin ${ }^{+}$colonies with myoblasts. Quantitative analysis indicated that only $0.6 \%$ of BMMCs formed myotubes, while $15.3 \%$ of NEMP cells could generate SMMts following initial differentiation (Fig. 3E).
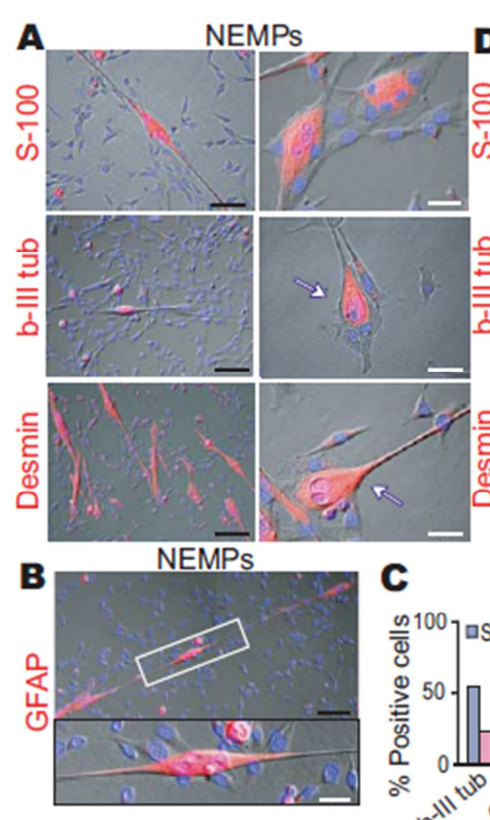
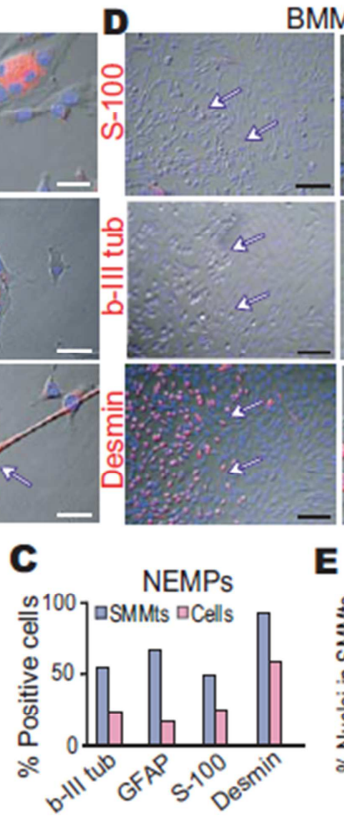

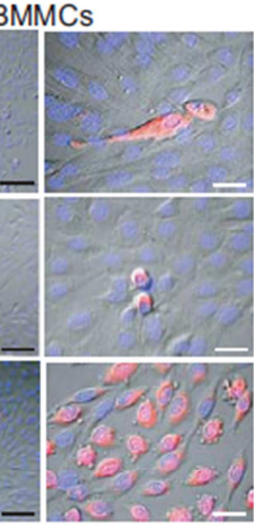

$\mathbf{E}$

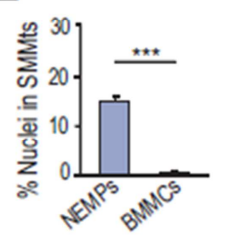

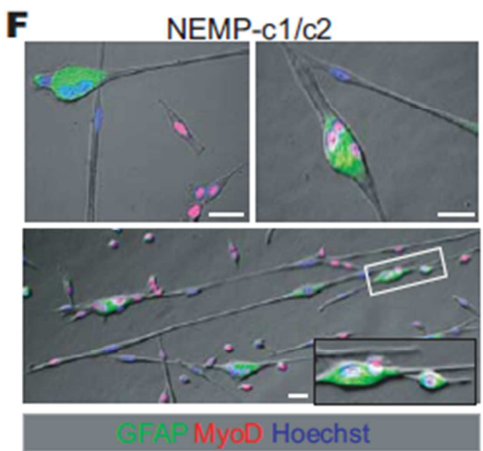

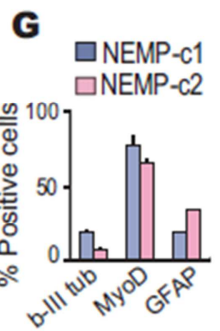

\section{H}

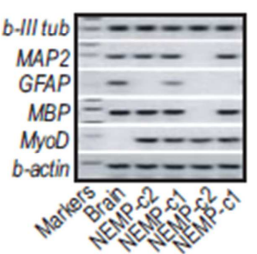

Figure 3. NEMPs, but Not BMMCs, Underwent Initial Neuromuscular Differentiation.

(A, B) Differential interference contrast (DIC) images merged with immunostaining show that radial glia-like cells (arrows) and SMMts expressed neural and myogenic markers in NEMP cultures.

(C) For each staining, 55-84 SMMts and 1130-1550 cells were counted.

(D) BMMCs generated S-100 $/$ beta-III tubulin ${ }^{-} /$desmin $^{+}$colonies (arrows).

(E) Percentage of cells fused into SMMts (mean \pm SEM, $n=5$ to 6 cultures, $* * * P<0.001$ ).

(F, G) NEMP-c1 and -c2 cells differentiated into $\mathrm{GFAP}^{+}$radial glia-like cells, GFAP ${ }^{+} \mathrm{MyoD}^{+}$cells, and SMMts. Quantitative analysis was carried out from two to three separate cultures.

(H) RT-PCR was performed with two samples from each cell type, confirming the neuromuscular phenotypes of SMMts. B-III tub and b-actin: beta-III tubulin and beta-actin.

White scale bars, $25 \mu \mathrm{m}$; black scale bars, $100 \mu \mathrm{m}$. 
Similar to NEMPs, NEMP-c1 and -c2 also differentiated into $\mathrm{GFAP}^{+}$radial glia-like cells, $\mathrm{MyoD}^{+} \mathrm{GFAP}^{+}$cells, and SMMts (Fig. 3F and 3G). RT-PCR confirmed the presence of beta-III tubulin, microtubule-associated protein 2 (MAP2, a neuronal marker), myelin basic protein $(M B P$, an oligodendrocyte marker) and $M y o D$ mRNAs in NEMP-c1 and -c2 cultures, as well as GFAP in NEMP-c1 (Fig. 3H). The SMMts resembled embryonic myotubes that formed in culture [33-35]; however, the neural commitment of NEMP cells to myotubes suggests a novel myogenic pathway.

\subsection{Long-Term Myotube Formation of BMMCs Versus \\ Limited Myogenic Potential of NEMPs in Culture}

In the growth medium, NEMP's early progeny rapidly lost their ability to fuse into SMMts. However, the NEMPs at $\mathrm{P}_{8-}$ 12 could undergo secondary myofiber formation in the differentiation medium, leading to many long and multinucleated myotubes (Fig. 4A), like the fetal myofibers [33-35]. By contrast, BMMCs maintained myotube formation from $\mathrm{P}_{8}$ to $\mathrm{P}_{20}$ (Fig. 4A). NEMP-c1/c2 could also generate multinucleated myotubes during differentiation (Fig.
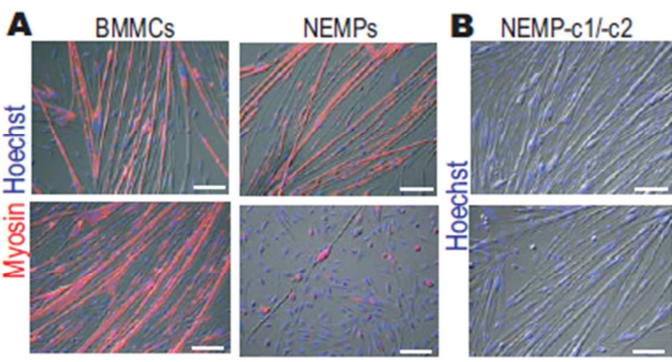

E

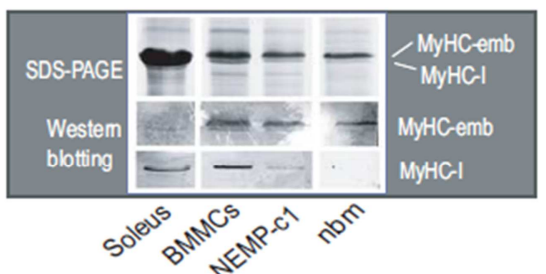

4B). The percentage of cells fused into myotubes was $81.8 \%$ in $\mathrm{P}_{8-12}$ and $5.2 \%$ in $\mathrm{P}_{16-20}$ of NEMPs, and $70.2 \%$ in $\mathrm{P}_{8-12}$ and $48.4 \%$ in $\mathrm{P}_{16-20}$ of BMMCs (Fig. 4C). The population doubling time of BMMCs was significantly shorter than that of NEMPs and NEMP-c1 (Fig. 4D). Thus, under the same culture conditions, BMMCs frequently produced more myotubes than NEMPs. To confirm the myotube phenotype, we examined myosin heavy chain (MyHC) isoforms and observed muscle-specific proteins MyHC-I and MyHCembryonic isoforms in BMMC- and NEMP-related myotubes (Fig. 4E).

We further investigated the nature of NEMP- $\mathrm{P}_{20}$ after 5day differentiation in the low serum medium. By skeletal myosin immunostaining, we observed well-developed SMMts consisted of multinucleated myotubes several millimeters in length in the cultures (Fig. 4F). By scanning three entire $60-\mathrm{mm}$ culture wells, three tissue-like SMMts expressing myosin were observed. The unique structure of these SMMts provided important evidence for a potential physiological role of NEMP's initial neuromuscular differentiation (Fig. 4G).

\section{C}

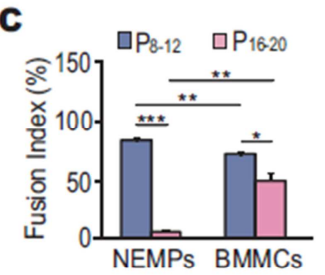

D
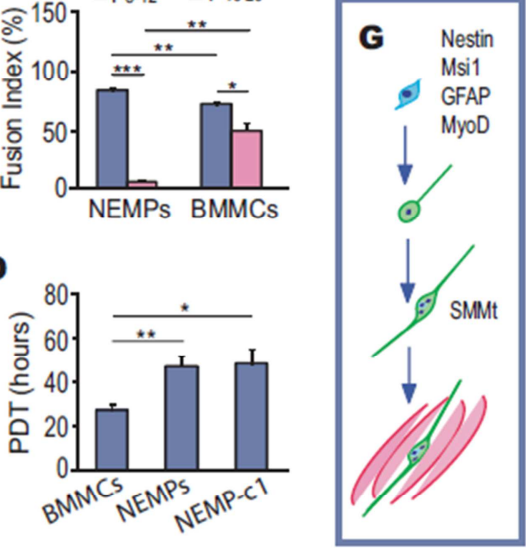

$\mathbf{F}$

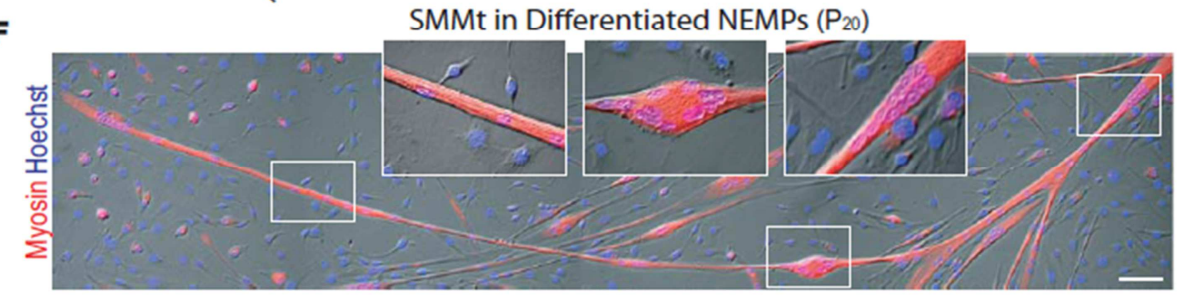

Figure 4. In Vitro Myotube Formation of NEMPs and BMMCs.

(A) Many long and multinucleated myotubes were generated by BMMC- and NEMP-P $\mathrm{P}_{8-12}$ (upper panels), and also BMMC- but not NEMP-P ${ }_{16-20}$ (lower panels).

(B) NEMP-c1 (upper) and -c2 (lower) could also generate myotubes.

(C) Fusion index was expressed by the percentage of nuclei in myotubes to total nuclei. Values represent mean $\pm \operatorname{SEM}(n=5$ to 6 individual trials, $* P<0.05$, ** $P<0.01, * * * P<0.001)$

(D) Population doubling time (PDT) was analyzed in $\mathrm{P}_{8-12}$ (mean $\pm \mathrm{SEM}, n=8$ cultures, ${ }^{*} P<0.05,{ }^{* *} P<0.01$ ).

(E) MyHC isoforms were identified in myotubes from $\mathrm{P}_{8-12}$. The adult soleus muscle and newborn muscle (nbm) were used as positive controls for MyHC-I (in soleus) and MyHC-embryonic bands (in nbm).

(F) A well-developed SMMt was present in differentiated NEMPs.

(G) Scheme shows the generation of SMMt and its hypothetical role in early muscle formation.

Scale bars, $100 \mu \mathrm{m}$ in A, B and F. 


\subsection{NEMPs and BMMCs Restored Dystrophin Expression but NEMPs Produced Embryonic/Fetal-Like Myofibers in Dystrophic Muscles}

To examine the transplantation capacity of the cells, we grafted NEMPs, NEMP-c1 and BMMCs into the gastrocnemius muscles of dystrophin-deficient $m d x$ mice, an animal model for DMD. Cells at $\mathrm{P}_{8-12}$ were used due to their proliferation and myotube formation in vitro. Numerous dystrophin ${ }^{+}$fibers were detected in the 14-day grafts of NEMPs and BMMCs (Fig. 5A), and also observed heterogeneously (3:10) in 40-50-day NEMP (Fig. 5B) and NEMP-c1 grafts (not shown). Notably, two types of NENP grafts were identified by distinct donor myofibers (Fig. $5 \mathrm{~A})$ : being large and centrally nucleated $(\mathrm{CNFs})$, or tiny and peripherally nucleated (PNFs). These myofibers resembled the skeletal muscle that formed during embryogenesis [35, 36], which is correlated with the phenotype of grafted cells $\left(\operatorname{Pax} 3^{\text {hi }} M y o D^{\text {hi }} M y f 5^{\text {hi }}\right)$. By contrast, the early grafts of BMMCs consisted of more homogeneous dystrophin ${ }^{+}$CNFs (Fig. 5A). Given the high percentage of $\mathrm{Pax}^{+} \mathrm{MyoD}^{+}$cells grafted, the central nucleation of BMMC fibers fits the characteristic of regenerating fibers developed from postnatal muscle precursors [37]. Interestingly, although the majority of BMMC myofibers were lost in eight late grafts of mdx mice (Fig. 5C), more than 800 healthy dystrophin ${ }^{+}$fibers were generated 35 days after grafting a small number of BMMCs $\left(5 \times 10^{4}\right)$ into irradiated muscles of $m d x \mathrm{nu} / \mathrm{nu}$ mice (Fig. 5D). The irradiation has been reported to inhibit endogenous myoblast activation, thus improving the longterm survival of donor myofibers [38].

Quantitative analysis revealed that the number of dystrophin $^{+}$fibers was high in the 14-day grafts of BMMCs and NEMPs, and decreased dramatically by $87 \%$ and $77 \%$ in 40-50-day grafts, but remained higher in grafted sites than non-grafted sites (Fig. 5E). The percentage of dystrophin ${ }^{+}$ CNFs in NEMP grafts was lower than that in the BMMC grafts (Fig. 5F). The dystrophin ${ }^{+}$fibers of NEMP-c1 were smaller than the fibers in non-grafted sites (Fig. 5G). Generally, BMMCs produced homogeneous dystrophin ${ }^{+}$ fibers in early grafts in terms of the percentage of CNFs (average $33.7 \%$, ranged $30.1 \%-36.0 \%$ ) and the relative diameter of fibers (average 18.0 $\mu \mathrm{m}$, ranged 17.6-18.6 $\mu \mathrm{m}$ ). By contrast, the grafts of NEMPs and NEMP-c1 were largely heterogeneous with regard to the number, nuclear location, and diameter of donor fibers. We observed ten grafts from 13 NEMP-injected muscles. Of these grafts, six had a low percentage of CNFs (average 11.9\%, ranged 9.9\%-17.1\%), five of which were correlated with the small diameter of fibers (average $13.3 \mu \mathrm{m}$ ). Four grafts had a higher percentage of CNFs (average $41.1 \%$, ranged $34.7 \%-47.7 \%$ ), three of which were correlated with the large diameter of myofibers (average $28.5 \mu \mathrm{m}$ ). In summary, NEMPs generated two major types of grafts resembling enlarged embryonic and fetal myofibers, which are distinct from the regenerating fibers of BMMCs (Fig. 5H).

Next, we analyzed the histological features of six late grafts that exhibited large numbers of dystrophin ${ }^{-}$fibers in the grafted sites (Fig. 5I). In the area, the percentage of dystrophin ${ }^{-}$PNFs was higher in NEMP/NEMP-c1 grafts than in BMMC grafts (Fig. 5J). In the NEMP/NEMP-c1-grafted sites, there were numerous small, rounded, regenerating PNFs, and increased endomysial tissue (Fig. 5I). These resembled the histopathological features of skeletal muscle disease, and were distinct from the satellite cell-regenerated CNFs (Fig. 5I). The presence of disease-like tissues provides an explanation for the loss of NEMP-derived dystrophin ${ }^{+}$ fibers in some of the late grafts.

\subsection{Maturation Analysis of Dystrophin ${ }^{+}$Fibers Associated with MyHC Expression and Muscle Satellite Cells}

To track the maturation of donor-related myofibers, we further examined the expression of developmental MyHC in the grafted muscles. The MyHC was detected in approximately $70 \%$ of dystrophin ${ }^{+}$fibers in the 14-day grafts of NEMPs, but was $<1 \%$ in the $40-50$-day grafts of NEMPs and NEMP-c1 (Fig. 6A and 6C). The results suggest that maturation of NEMP myofibers in host muscle had occurred. Interestingly, $>99 \%$ of BMMC fibers did not express development MyHC in the 14- and 40-50-day grafts (Fig. 6B and $6 \mathrm{C}$ ). The findings indicated that the majority of NEMP fibers were homogeneous in donor origin, while the dominant dystrophin ${ }^{+}$fibers in BMMC grafts were heterotypic, a result from fusion of donor cells with host fibers or myoblasts [39].

We then examined whether adult muscle progenitors existed in the grafts. Following transplantation, $\mathrm{Pax} 7^{+}$cells were detected in BMMC, NEMP and NEMP-c1 grafts (Fig. $6 \mathrm{D})$. In the early grafts, the number of $\mathrm{Pax} 7^{+}$cells in NEMP-grafted sites was 2.8-fold greater than that in BMMC-grafted sites (Fig. 6F). Analysis of MyoD, which is expressed in activated but not quiescent adult myoblasts $[40,41]$, showed that no differences were observed between $\mathrm{Pax} 7^{+}$and $\mathrm{MyoD}^{+}$cells in BMMC grafts, while Pax $7^{+}$cells were 3.3-fold greater than $\mathrm{MyoD}^{+}$cells in NEMP grafts. Consistent with the phenotype, large numbers of donor fibers in NEMP grafts remained small and peripherally nucleated, which did not support an adult myoblast function of the $\mathrm{Pax}^{+}$cells, because satellite cell-mediated muscle regeneration in adults will result in the fuse of cells into CNFs [37, 42]. Notably, in the most significant late graft of NEMPs with more than 800 donor myofibers, $10.6 \%$ of $\mathrm{CNFs}$, and myofiber diameter of $21.5 \mu \mathrm{m}$, we were unable to detect clear Pax $7^{+}$satellite cells (Fig. 6E). Thus, growth of these myofibers is independent of the $\mathrm{Pax} 7^{+}$cells observed in the early NEMP grafts. Together, the results indicate that BMMCs function as more committed muscle precursors, but the NEMP myofibers encounter impaired maturation with a defective adult fate in vivo, as characterized by the presence of non-fusing $\mathrm{Pax}^{+}$cells or the lack of satellite cells in grafts. 


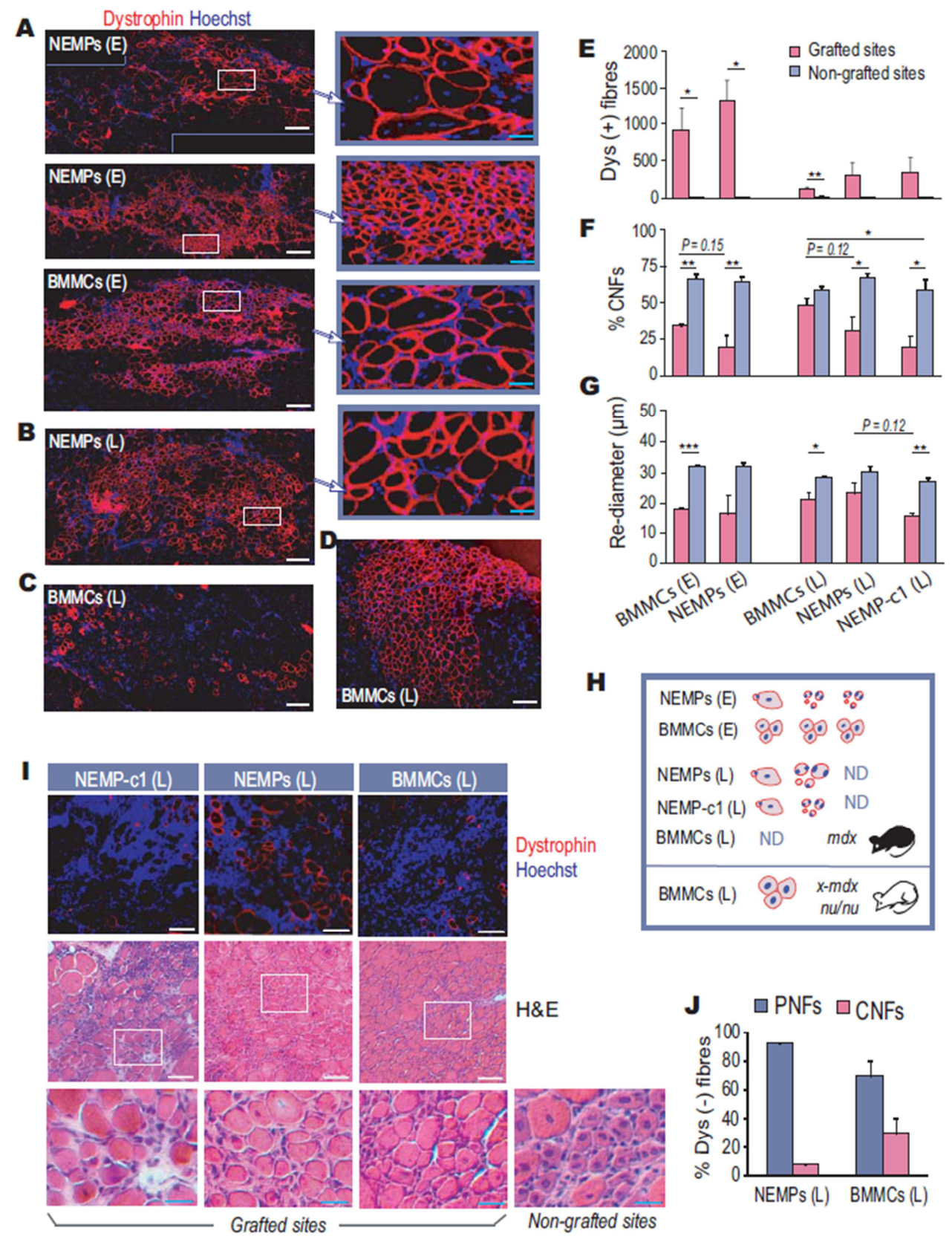

Figure 5. NEMPs and BMMCs Generated Distinct Myofibers in Dystrophic Mice.

(A) Dystrophin ${ }^{+}$fibers in three early grafts (E). The box areas in the left panels were magnified in the right panels showing large CNFs (upper) or small PNFs (middle) in NEMPs, and more uniform CNFs in BMMCs (lower).

(B) Many PNFs were present in one of the NEMP's late grafts.

(C) Dystrophin ${ }^{+}$fibers decreased dramatically in BMMC late grafts.

(D) BMMCs generated large late grafts in irradiated $m d x$ nu/nu mice.

(E-G) Quantitative analysis of dystrophin ${ }^{+}\left(\right.$dys $\left.^{+}\right)$fibers in mdx mice (mean \pm SEM, $\mathrm{n}=3,3,8,5$ and 5 muscles in E, and $\mathrm{n}=3-6$ muscles in F and G, * $P \leq$ $0.05, * * P<0.01, * * * P<0.001)$. The number of dys ${ }^{+}$fibers has been normalized to the number of injected cells in $\mathrm{E}\left(3 \times 10^{5}\right.$ cells $)$. The muscles with low numbers of dys ${ }^{+}$fibers are not shown in F and G: in this case, the data were impossible to interpret due to the presence of revertant fibers from spontaneous mutations [59]. Re-diameter: Relative diameter.

(H) Scheme summarizes two types of NEMP grafts with embryonic- or fetal-like myofibers, and homogeneous BMMC grafts with regenerating fibers. ND: No grafts with large clusters of dys ${ }^{+}$fibers ( $>50$ fibers) were detected.

(I) Serial sections of three muscles show disorganized dystrophin ${ }^{-}$PNFs and increased interstitial tissues in NEMP-grafted sites, histopathologically distinct from satellite cell-regenerated CNFs in non-grafted sites.

(J) The percentage of dys- - PNFs and dys ${ }^{-}-\mathrm{CNF}$ in grafted sites (mean \pm SEM, $\mathrm{n}=3$ muscles).

White scale bars, $150 \mu \mathrm{m}$ in A-D; $75 \mu \mathrm{m}$ in I; Blue scale bars, $25 \mu \mathrm{m}$ in A, B and I. 


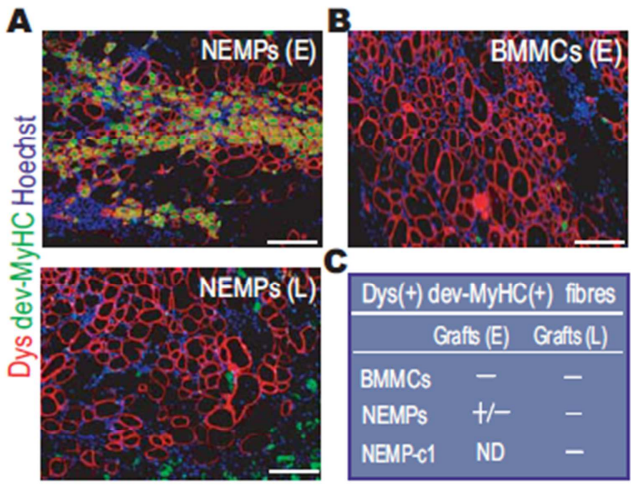

E

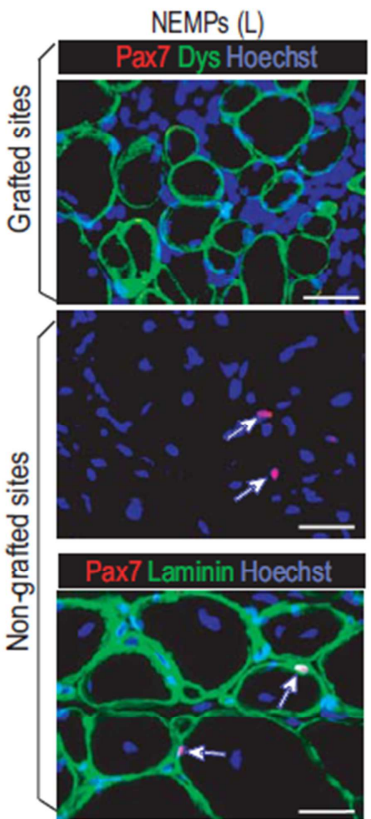

D
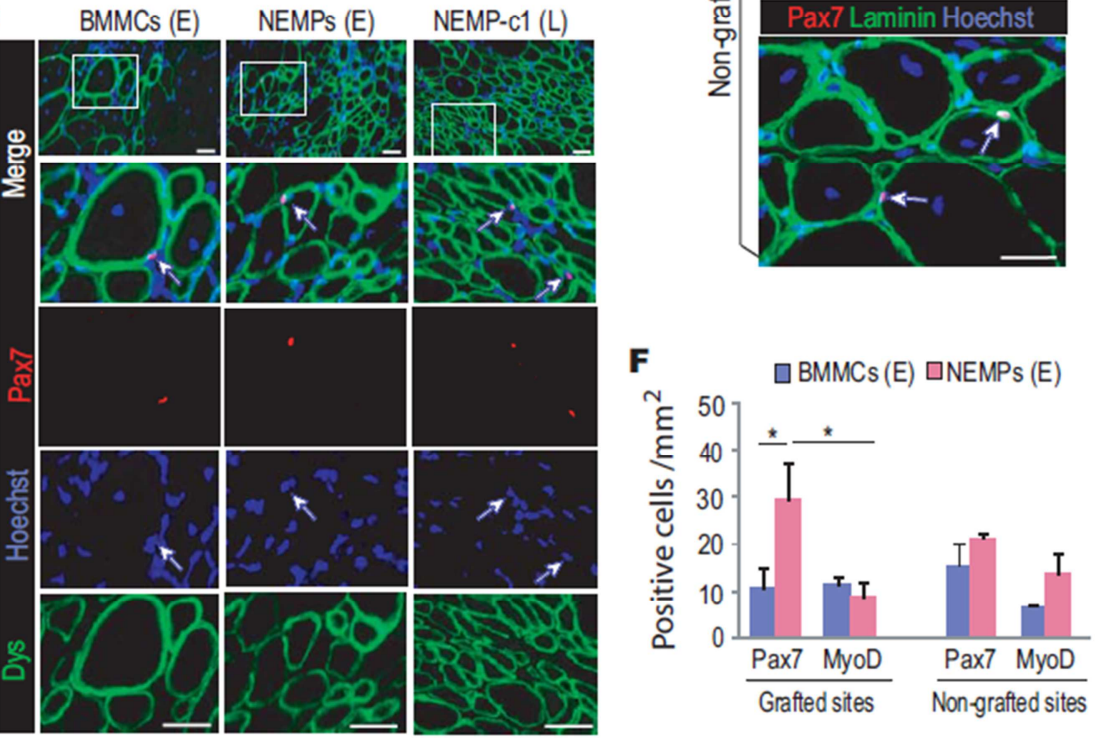

Figure 6. Differential Maturation of Dystrophin ${ }^{+}$Fibers from NEMPs and BMMCs.

(A, B) Dystrophin (dys) and developmental MyHC (dev-MyHC) double immunostaining of the early (E) and late grafts (L).

(C) Dev-MyHC ${ }^{+}$myofibers per 100 dys $^{+}$fibers:,$- 0-0.2 \%$;,$+- 71.5 \%$. Each value represents the mean of three muscles. ND: Not determined.

(D) Pax $7^{+}$cells (arrows) in CNFs (left panels) or small PNFs (middle and right panels).

(E) Same muscle section of a late NEMP graft shows no Pax $7^{+}$cells in grafted sites, and Pax $7^{+}$cells (arrows) in non-grafted sites, where CNFs were revealed by laminin staining in a serial section.

(F) Histogram shows no differences between Pax $7^{+}$and $\mathrm{MyoD}^{+}$cells in $\mathrm{BMMC}$-grafted sites, but higher Pax $7^{+}$cells than MyoD ${ }^{+}$cells in NEMP-grafted sites (mean \pm SEM, $\mathrm{n}=3$ muscles, $* P<0.05$ ).

Scale bars, $100 \mu \mathrm{m}$ in $\mathrm{A}$ and $\mathrm{B} ; 25 \mu \mathrm{m}$ in D and $\mathrm{E}$.

\subsection{Multi-Lineage Neural Differentiation of NEMPs Versus Limited Neural Potential of BMMCs}

Based on the initial neuromuscular differentiation of NEMPs, we then investigated the neurogenic potential of NEMP-P ${ }_{8-12}$, compared with BMMCs. In standard culture conditions, we observed higher levels of neuronal transcripts beta-III tubulin and MAP2 in NEMPs and NEMP-c1, and a high level of NG2 (a marker for oligodendrocytes and pericytes) in BMMCs (Fig. 7A). When cultured in the neurosphere formation and differentiation conditions supplemented with brain-derived neurotrophic factor, MAP $2^{+}$ and beta-III tubulin/Tuj $1^{+}$cells were observed in all the populations, some of which had typical neuronal morphology, especially in the NEMP-c1 (Fig. 7B and 7C). Very few of BMMCs showed the morphology of neurons.
Thus, the generation of neurons in NEMP populations correlates with their higher expression of neuronal transcripts in the untreated cells. RT-PCR confirmed the expression of lineage markers for neurons and oligodendrocytes in the treated NEMP cells and BMMCs (Fig. 7D). In particular, astrocyte marker GFAP was detected in both treated and untreated NEMPs. The findings demonstrate multi-lineage neural differentiation of NEMP-P ${ }_{8-12}$. However, given the defective adult fate for the myogenic lineage, it remains unknown whether mature neurons could be established from the embryonic-like progenitors.

Next, we developed NEMP clones by seeding single cells into the 96-well plates. After isolation and expansion for a short period, analysis of two clones revealed that clone 1 displayed low levels of Msi1, high levels of NSE (neuronspecific enolase), and $31.6 \%$ of $\mathrm{MyoD}^{+}$cells, while the clone 
2 showed high levels of Msi1, low levels of NSE, and only $1.1 \%$ of $\mathrm{MyoD}^{+}$cells (Fig. 7E). Thus, single cells from NEMPs differentiated into neural and muscle cells.

Due to the glial differentiation in vitro, we tracked NEMPc1 in four grafted muscles of female mice by FISH analysis, and detected Y-chromosome ${ }^{+}$cells at a low frequency in the peripheral nerves $(6.88 \pm 0.43$, mean \pm SEM, $n=4$ muscle samples; $0, \mathrm{n}=3$ control samples, average of 15 sections per sample). Immunostaining revealed some $\mathrm{Y}$-chromosome ${ }^{+}$ cells relevant to GFAP-expressing glial cells (Fig. 7F).

A

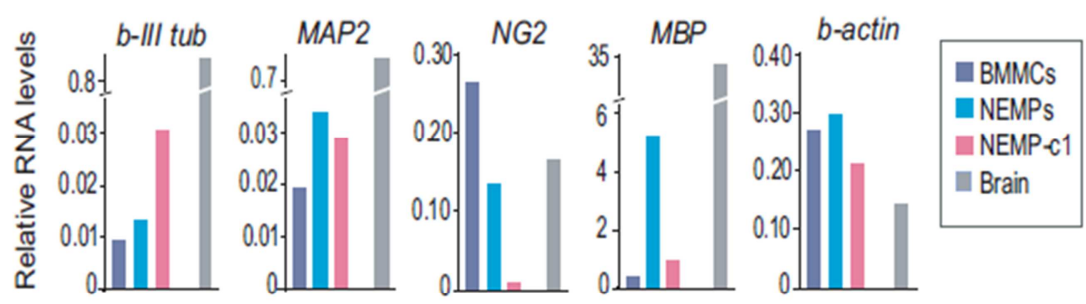

$\mathbf{B}$

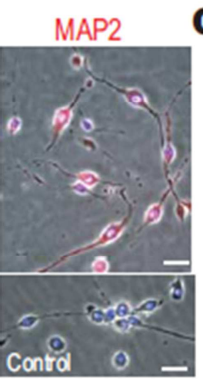

C MAP2

MAP2

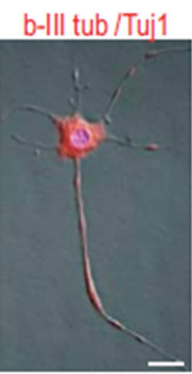

D

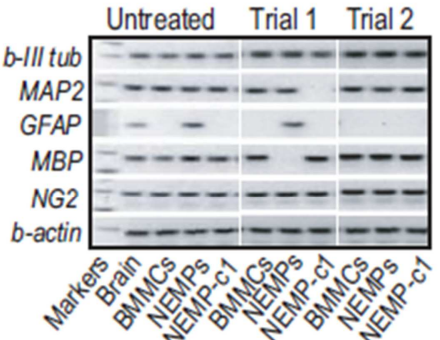

E

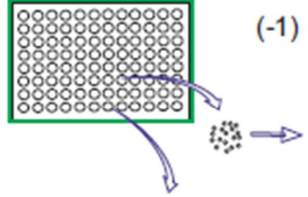

$(-1)$
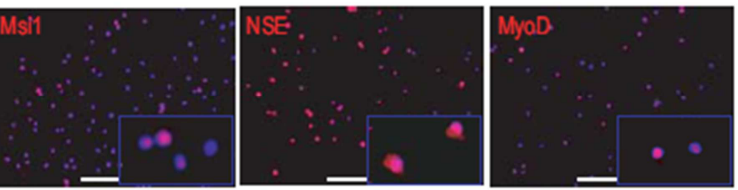

$(-2)$
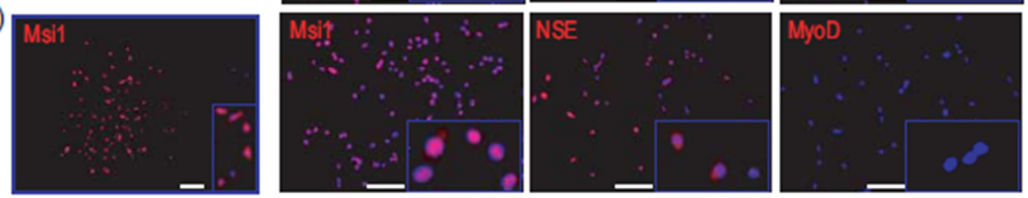

$\mathbf{F}$
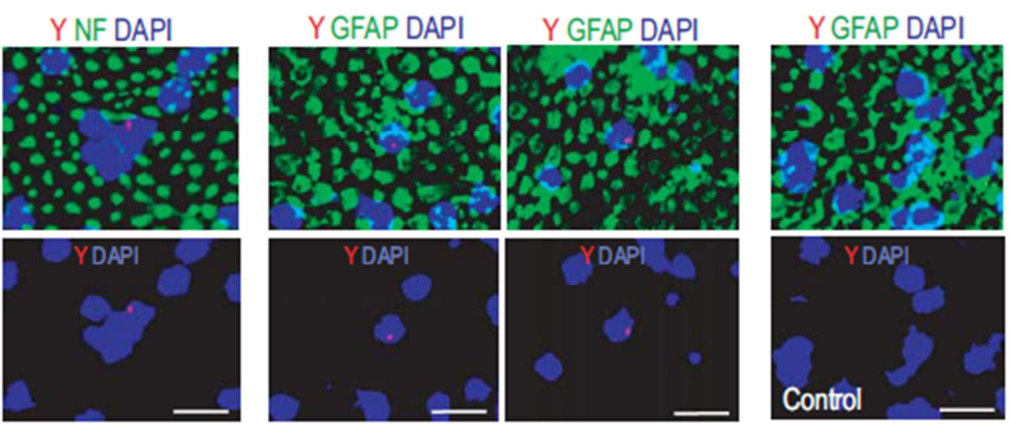

Figure 7. Multi-Lineage Neural Differentiation of NEMPs versus Limited Neural Potential of BMMCs.

(A) Quantitative RT-PCR was performed with untreated cells in two samples from each cell type, showing higher levels of beta-III tubulin and MAP2 in NEMP cells and higher $N G 2$ in BMMCs.

(B, C) Cells were treated by neurosphere formation and differentiation, and expressed neuronal markers in the cultures of NEMP-c1.

(D) Transcripts were measured by RT-PCR and adult brain tissues were used as the positive control. Both untreated and treated cells expressed identical mRNAs with the exception that MAP2 and MBP were not detected in the treated NEMP-c1 or NEMPs in Trial 1, but were expressed in Trial 2 when laminin was added into the neurobasal medium. GFAP was only detected in NEMPs.

(E) Two single clones were established from cultured NEMPs, and analyzed for the expression of Msi1, NSE and MyoD. Note that clone 2 (-2) generated a new clone (Msi $1^{\text {hi }}$, lower left panel) during expansion. Nuclei were stained by Hoechst.

(F) Y chromosomes were detected in peripheral nerves of NEMP-c1-grafted muscles. NF: Neurofilament.

Scale bars, $25 \mu \mathrm{m}$ in $\mathrm{B} ; 15 \mu \mathrm{m}$ in $\mathrm{C}$ and $\mathrm{F} ; 100 \mu \mathrm{m}$ in $\mathrm{E}$. 


\section{Discussion}

In the present study, we have demonstrated two new types of multipotent myogenic progenitors from adult skeletal muscle and bone marrow. The differentiation of NEMPs into radial glial and embryonic/fetal myoblast lineages has been the first report by using muscle cell isolations. In addition, the isolation of myogenic cells from bone marrow supports previous observations [5, 7], but also provides additional evidence for a distinct subset of bone marrow, capable of generating muscle cells for more than 50 population doublings. The original NEMPs are considered to be one cell per $130 \mathrm{mg}$ mouse muscle. The rarity and lack of a physiological role to postnatal muscle tissue suggest the potential identity of NEMPs as embryonic remnants. This character distinguish NEMPs from subpopulations of muscle satellite cells [16-18, 43], or muscle-derived pericytes and interstitial progenitors [44-46], which are relative abundance in tissue (hundreds or thousands of sorted cells per $100 \mathrm{mg}$ muscle), and functionally related to postnatal muscle, vasculature or connective tissues. However, whether NEMPs exist in some of the muscle-based cell cultures is unknown, and their potential impact on the biological behaviors of these cells needs to be established. Notably, the vascularrelated progenitors (pericytes or mesoangioblasts) have been presumed to represent embryonic cells present in the postnatal tissue [44]. It might be interesting to examine whether the multi-lineage differentiation of such cells is related to an embryonic fate.

In a previous report, a small population of CD $34^{+} / \mathrm{Sca}-1^{+}$ progenitors was isolated from muscle of newborns, which exhibited extensive proliferation as myogenic cells for 30 passages [6]. Interestingly, we did not find a similar population in adult skeletal muscle, despite analyzing multiple primary colonies from 5-, 7- and 10-week-old mice. A reasonable explanation for this discrepancy is that the $\mathrm{CD} 34^{+} / \mathrm{Sca}^{+}{ }^{+}$cells represent a distinct high-proliferating myogenic population in newborn muscles [47, 48], which may overgrow to replace the slow-dividing NEMPs when the initial culture contains both cell types.

The distinct myogenic fates of NEMPs and BMMCs suggest that their differentiation in vitro might mimic distinctive stages in muscle development. During limb myogenesis, $\mathrm{Pax}^{+}$muscle progenitors differentiate into MyoD and Myf5-expressing embryonic and fetal myoblasts that form different stages of skeletal muscle in embryos [2931]. At postnatal stage, quiescent adult myoblasts/satellite cells expressed Pax7 [49], and also MyoD and/or Myf5 when activated, to produce regenerating myofibers [40, 41]. Compared to this model, early activated BMMCs expressed a higher level of Myf5 and produced $\mathrm{Pax}^{+} \mathrm{MyoD}^{+}$adult myoblasts for more than 50 population doublings. By contrast, NEMPs generated two waves of myogenic cells by a temporal manner: initial up-regulation of Pax3 in early passages and a higher level of MyoD/Myf5 in late passages, similar to embryonic and fetal myogenic pathways. The different expression patterns of myogenic markers in NEMPs and BMMCs were further confirmed by their respective generation of distinct myotubes/myofibers in culture and in transplants. The findings demonstrate that after activation in vitro, the NEMPs function as embryonic muscle progenitors, while the BMMCs serve as postnatal myogenic precursors (Fig. 8).

Neurogenic conversion of muscle-derived cells has been examined $[50,51]$; the present study, however, was designed to characterize a novel type of neurogenic/myogenic progenitors from skeletal muscle. The activated NEMP cells expressed high levels of neural progenitor markers nestin, Msi1 and GFAP [28, 32], and could generate radial glia and neurons in culture. Radial glial cells normally arise from the embryonic neuroepithelium and function to guide migration of immature neurons [52]. Our findings, therefore, support the NEMPs as embryonic neural progenitors present in postnatal skeletal muscle. The co-expression of MyoD and GFAP in the activated single NEMPs and their spontaneous differentiation into radial glia-associated myotubes/SMMts demonstrate a unique progenitor for both neuroepithelial and myogenic lineages. Although similar progenitors have not been reported previously, the co-presence of cells with muscle, glial and neuronal phenotypes in rhabdomyosarcoma [23] suggests the existence of such progenitors in postnatal muscle. In the present study, we did not explore the potential location of NEMPs in tissue. Based on the generation of SMMts, we hypothesize a possible source of NEMPs in association with a small number of neuromuscular spindles, the stretch receptor organs within skeletal muscle.

Transplantation experiments demonstrated distinct roles of NEMPs and BMMCs in muscle regeneration. The BMMCs established healthy engraftments in $m d x$ (early grafts) and irradiated $m d x n u / n u$ mice, the latter showing one of the best engraftments with this animal model [16]. Because one BMMC can produce at least $10^{9}$ muscle cells, it provides efficient myogenic precursors in cell replacement strategy. The generation of large numbers of dystrophin ${ }^{+}$myofibers by BMMCs also demonstrates the in vivo muscle differentiation of marrow-derived cells [5, 7] rather than a simply nonmyogenic fusion. By contrast, the NEMP cells produced unusual grafts with embryonic/fetal-like dystrophin ${ }^{+}$ myofibers that could, to some extent, adapt to a postnatal differentiation program, leading to the long-term survival of engraftments. However, the presence of $\operatorname{Pax} 7^{+}$non-fusing cells or the lack of satellite cells in grafts suggests abnormal or restricted adult fates of NEMPs in vivo, presumably due to their intrinsic differentiation potential and the lack of a normal developmental niche in the dystrophic muscles.

In cell transplantation, mdx mice, which lack dystrophin in the membrane of muscle fibers, were used. Compared with DMD patients, the $\mathrm{mdx}$ mice show less severe myopathology, and efficient muscle regeneration, resulting 
in more than $50 \%$ of CNFs in the adult animals $[42,53]$. However, grafting of NEMPs altered the histopathological features of mdx muscle to that similar to DMD patients. First, NEMPs produced fetal-like myofibers or regenerating myofibers with a low percentage of CNFs, which has only been reported in patients with DMD [54], and in the extensively damaged diaphragm of mdx mice [55]. Second, the fetal-like grafts lacking satellite cells or showing increased number of non-fusing $\mathrm{Pax} 7^{+}$cells is in agreement with the features of satellite cell deficiency [56], or the presence of defective satellite cells in DMD patients [57, 58]. Third, dystrophin ${ }^{-}$fetal-like fibers existed in grafted sites. The recapitulation of DMD patient's muscle tissue suggests that activated primitive NEMPs and their early myogenic progeny are potentially associated with DMD pathogenesis, and should be excluded in cell transplantation for repair of muscle damage in this myopathy.

In conclusion, we have demonstrated that embryonic-like neural/muscle progenitors can be isolated from adult skeletal muscle, and differentiate in vivo into fetal-like muscles recapitulating myofiber and satellite cell abnormalities of DMD patients, thus representing a potential cellular origin of diseased tissues. In parallel studies, bone marrow-derived progenitors contribute to adult muscle precursors capable of repairing dystrophic mice. Identification of the two types of embryonic- and adult-like progenitors may have different implications in cell replacement strategy, and enhance our understanding the etiology and progression of relevant human diseases. Based on the embryonic fate and lack of physiological roles, we suggest that the adult-origin NEMPs may provide a unique disease-associated cell type for therapeutic development.

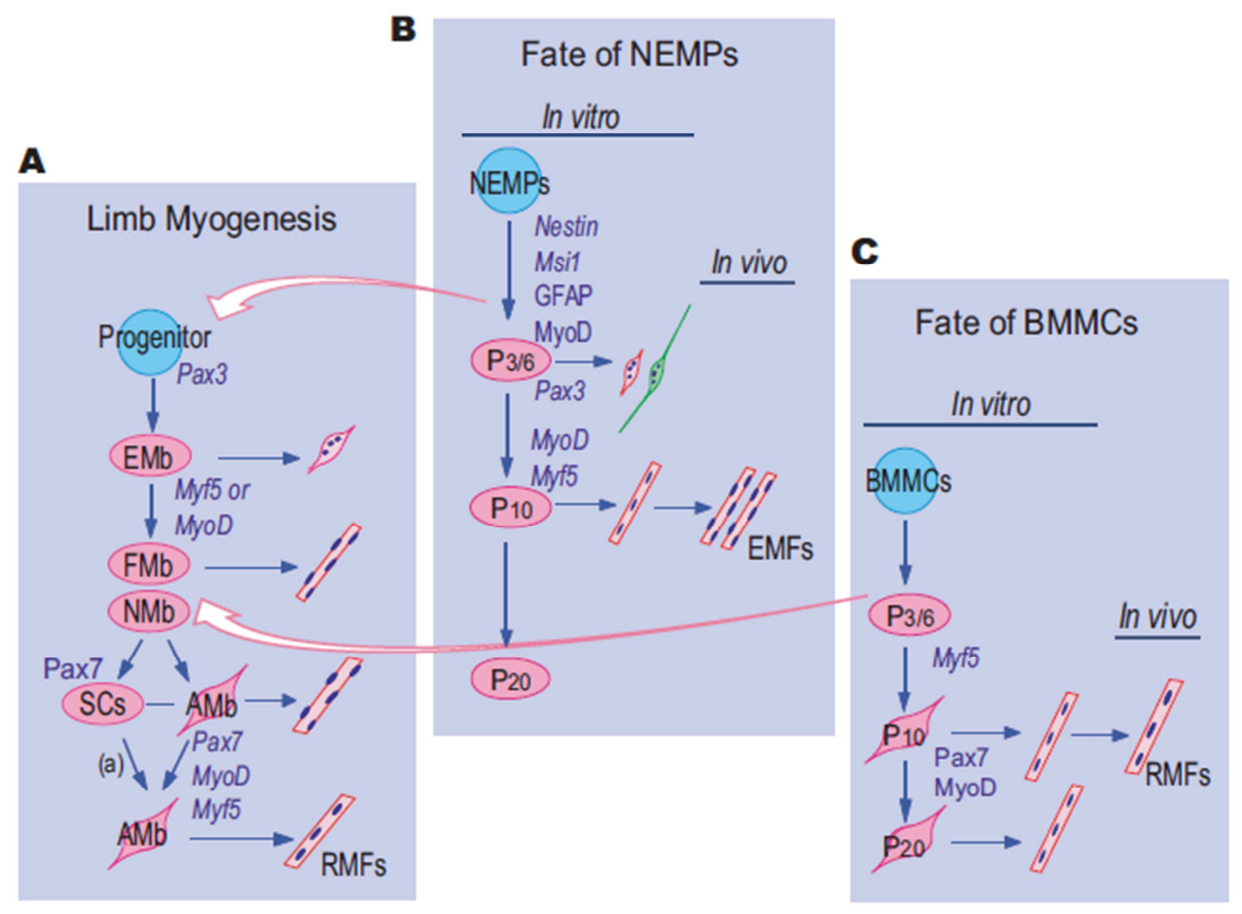

Figure 8. The Differentiation Hierarchy and Cell Fate of NEMPs and BMMCs Compared with Limb Myogenesis.

(A) During myogenesis, muscle progenitors $\left(\mathrm{Pax}^{+}\right)$differentiate into embryonic (EMb), fetal (FMb), and neonatal/adult myoblasts $(\mathrm{NMb} / \mathrm{AMb})$, which generate different stages of skeletal muscles. In adults, quiescent satellite cells (SCs) express Pax7, and also MyoD and Myf5 when activated (a), to produce regenerating myofibers (RMFs).

(B) The activated NEMPs express neuroepithelial and myogenic progenitor markers, and differentiate into early myoblasts that form embryonic/fetal-like myofibers (EMFs) in vivo.

(C) BMMCs can differentiate into adult-like myoblasts $\left(\mathrm{Pax}^{+} / \mathrm{MyoD}^{+}\right)$that regenerate dystrophic muscles. Large arrows indicate the NEMP and BMMC hierarchy in association with limb myogenesis.

\section{Abbreviations}

BMMCs, bone marrow myogenic cells; CNFs \& PNFs, centrally or peripherally nucleated fibers; $\mathrm{MyHC}$, myosin heavy chain; DMD, Duchenne muscular dystrophy; GFAP, glial fibrillary acidic protein; MAP2, microtubule-associated protein 2; MBP, myelin basic protein; NEMPs, neuroepithelial myogenic progenitors; SMMts, spindleshaped mosaic myotubes

\section{Supplementary Information (Experimental Procedures)}

\section{Animals}

Normal C57BL/6 mice, and $m d x$ mice (C57BL/10ScSn$\mathrm{Dmd}^{m d x} / \mathrm{J}$, purchased from Jackson Laboratories, USA) were used in this study. The mice were maintained in the Animal Facilities of the Panum Institute, University of Copenhagen 
and the animal protocols were approved by the Animal Care and Ethics Committee in Copenhagen.

\section{Cell Isolation}

NEMPs were isolated from skeletal muscle of C57BL/6 mice (five weeks old). Briefly, the hindlimb muscles were digested by $0.2 \%$ collagenase-type XI (Sigma-Aldrich) at $37^{\circ} \mathrm{C}$ for $1 \mathrm{~h}, 0.25 \%$ dispase for $45 \mathrm{~min}$, and $0.1 \%$ trypsinEDTA for $30 \mathrm{~min}$. The cells were then filtered through a 70 $\mu \mathrm{m}$ nylon mesh (BD Biosciences) and centrifuged at 3500 $\mathrm{r} / \mathrm{min}$ for $5 \mathrm{~min}$. The pellets were resuspended in the growth medium, and the cells were plated onto $0.01 \%$ collagen type 1-coated flasks (BD Biosciences) and cultured in a humidified incubator at $37^{\circ} \mathrm{C}$ with $5 \% \mathrm{CO}_{2}$. The growth medium consisted of DMEM supplemented with $10 \%$ horse serum, $10 \%$ fetal bovine serum, $0.5 \%$ chick embryo extract (Sera Laboratory International), and $1 \%$ penicillinstreptomycin (all reagents were purchased from Life Technologies unless stated otherwise). The primitive NEMPs took 5-6 days to attach to culture flasks, and thus they can be separated by preplate from the majority of cells that attached during the first 4 days $[6,25,26]$. On day 5 , the floating cells were collected and centrifuged. The pellets were resuspended in the growth medium and seeded onto 12-well dishes at $\sim 15-30$ cells $/ \mathrm{cm}^{2}$ to develop NEMP clones from primary cultures. During the following 2 weeks, the medium were changed daily and the initial NEMP colonies with 50-100 cells were formed. The early NEMP cells were small round or spindle-shaped, and phase-bright. To confirm the clonal property, the primary colonies were picked up, and seeded in new 12-well dishes at the clonal density. When new colonies were formed within another two weeks, the wells containing single colonies were chosen as the primary NEMP clones. Colony cylinders (Sigma-Aldrich) were used to select primary colonies or purified clones.

To isolate BMMCs, the femurs of $\mathrm{C} 57 \mathrm{BL} / 6$ mice (seven weeks old) were removed, and the bone marrow was flushed out with HBSS using a 25-gauge needle. The bone marrow samples were centrifuged at $3500 \mathrm{r} / \mathrm{min}$ for $5 \mathrm{~min}$, and the cells were collected and incubated with muscle extract for 30 min. To prepare the muscle extract, $300 \mathrm{mg}$ of hindlimb muscle of normal mice was minced and incubated in $5 \mathrm{ml}$ of $0.2 \%$ collagenase-type XI (Sigma-Aldrich) at $37^{\circ} \mathrm{C}$ for one hour, and then centrifuged at $3500 \mathrm{r} / \mathrm{min}$ for $5 \mathrm{~min}$. The supernatant (collagenase-muscle extract) was collected and filtered through $0.2-0.4 \mu \mathrm{m}$ pores to avoid muscle cell contamination. We checked the filtered muscle extract and did not find cells in it. Although we do not know the precise function of the muscle extract, in a pilot study, no myogeniclike cells were present in cultures when marrow cells were not treated with muscle extract, suggesting its potential role for inducing muscle differentiation of bone marrow. After incubation with muscle extract, the bone marrow cells were centrifuged, and resuspended in the growth medium. The cells were cultured in a collagen-coated flask, and further separated by preplate and clonal isolation as described for NEMPs.

\section{Neural Differentiation}

The neurosphere formation and differentiation were performed as described [50], with modification. In brief, cells were cultured in non-coated 6-well plates in neurobasal medium supplemented with $1 \%$ penicillin-streptomycin, Lglutamine $(2 \mathrm{mM}), \mathrm{B} 27$, basic fibroblast growth factor (bFGF, $20 \mathrm{ng} / \mathrm{ml}$ ), and epidermal growth factor (EGF, 20 $\mathrm{ng} / \mathrm{ml})$. Neurospheres were present after 1 day and were grown for 5 days. The cells were then switched to poly-Llysine-coated plates in neurobasal medium supplemented with N2, EGF (20 ng/ml), bFGF (20 ng/ml), L-glutamine and laminin ( $1 \mu \mathrm{g} / \mathrm{ml}$, Sigma-Aldrich) for 1 day. Afterwards, the cells were incubated in neurobasal medium with $\mathrm{N} 2$, brainderived neurotrophic factor $(15 \mathrm{ng} / \mathrm{ml})$ and laminin for 2-3 days (all reagents were purchased from Life Technologies unless stated elsewhere). Expression of specific markers for neuronal and glial lineages in the untreated and treated cells was determined by immunocytochemistry, RT-PCR and realtime RT-PCR.

\section{Isolation and Analysis of NEMP Clones}

NEMPs $\left(\mathrm{P}_{16}\right)$ were plated onto collagen type 1-coated 96well dishes at a density of $25-50$ cells $/ \mathrm{ml}$ medium, and checked for single cells $1 \mathrm{~h}$ after plating. The cells were grown in the growth medium for six days, and single clones were picked up for further expansion. Expression of specific markers for muscle (MyoD) and neural cell lineages (Msi1 and NSE) in two clones was determined by immunocytochemistry.

\section{Immunocytochemistry}

Cells were fixed in cold methanol for 5-10 min, washed in PBS and blocked in 5\% serum or $1 \%$ bovine serum albumin for $30 \mathrm{~min}$ at room temperature. Primary antibodies used in this study were rabbit anti-desmin (1:100, Sigma-Aldrich), mouse anti-MyoD (1:80, BD Biosciences), mouse antimyogenin (1:80, BD Biosciences), mouse anti-Pax7 (1:50, R\&D Systems), goat anti-Wnt-1 (1:20, R\&D Systems), rabbit anti-Msi1 (1:100, Abcam), rabbit anti-Nanog (1:100, Abcam), mouse anti-Pax3 (1:100, R\&D Systems), rabbit anti-S-100 (1:300, Sigma-Aldrich), rabbit anti-GFAP (1:200, Sigma-Aldrich), mouse anti-beta-III tubulin (1:300, Millipore), mouse anti-beta-III tubulin/Tuj1 (1:200, R\&D Systems), rabbit anti-MAP2 (1:600, Millipore), rabbit antiNSE (1:100, Sigma-Aldrich), and mouse anti-skeletal myosin fast (1:500, Sigma-Aldrich). Staining was revealed by species-specific Alexa Fluor 594 or 488 (1:500, Life Technologies). The nuclei were revealed by Hoechst 33342 (Sigma-Aldrich). The percentage of positive cells was determined as the ratio of labeled cells to the total number of cells in five randomly chosen fields at $100 \times$ or $200 \times$ magnification. The cells labeled only with secondary antibody, or with irrelevant antibodies were used as negative controls. Fluorescent images were performed using an Olympus IX71 inverted microscope. 


\section{Flow Cytometry}

NEMPs and BMMCs were grown in $75-\mathrm{cm}^{2}$ flasks until $15-25 \%$ confluence. The cells were then detached with cell scrapers (Sigma-Aldrich) and spun down. Staining was done in PBS containing $1 \%$ BSA at $4^{\circ} \mathrm{C}$. FITC- or R-PEconjugated monoclonal antibodies to Sca-1 (BD Pharmingen), CD133 (eBioscience), CD34 (BD Pharmingen), CD24 (Millipore), and Bcrp1/ABCG2 (Millipore) were used. Flow cytometry was performed using EPICS XL-MCL flow cytometer (Coulter) and the percentage of positive cells was assessed by Winlist software.

\section{Sodium Dodecyl Sulfate Polyacrylamide Gel Electrophoresis (SDS-PAGE) and Western Blotting}

Myosin heavy chain isoform analysis was performed using SDS-PAGE. To determine the MyHC isoform composition in the BMMCs and NEMP-c1 cells, a 10-25 $\mu 1$ pellet obtained from the myotube cultures of each cell population, was dissolved in $150 \mu \mathrm{l} \mathrm{HBSS}$, mixed with $350 \mu \mathrm{l}$ Laemmli sample buffer and heated for $4 \mathrm{~min}$ at $90^{\circ} \mathrm{C}$. Twenty to seventy-five milligrams of muscle from the soleus muscle of adult C57BL/6 mice, and entire legs from newborn C57BL/6 mice, were homogenized in 350-750 $\mu$ l Laemmli sample buffer and heated for $4 \mathrm{~min}$ at $90^{\circ} \mathrm{C}$. The myosin-containing samples $(8-25 \mu \mathrm{l})$ were loaded on an SDS-PAGE gel containing $6 \%$ polyacrylamide and $30 \%$ glycerol. Gels were run at $4^{\circ} \mathrm{C}$ at $70 \mathrm{~V}$ for $42-44 \mathrm{~h}$. Subsequently, one set of gels was stained with Coomassie Blue to visualize the MyHC bands directly. Another set of gels was blotted onto a PVDF membrane at $500 \mathrm{~mA}$ overnight. Membranes were blocked with 5\% skimmed milk powder overnight, washed with TBS$\mathrm{T}$ and incubated with the primary antibodies BA-F8 (antiMyHC-I, 1:100) and BF-G6 (anti-MyHC-embryonic, 1:50) [60] for $2 \mathrm{~h}$ at $37^{\circ} \mathrm{C}$, washed in TBS-T and incubated in the secondary antibody $\left(1: 600\right.$, Dako) for $1 \mathrm{~h}$ at $37^{\circ} \mathrm{C}$, and finally developed with DAD.

\section{Real-Time RT-PCR}

Total RNA from 5,000-50,000 cells was purified using $150 \mu \mathrm{l}$ TriReagent (Molecular Research Center) containing $80 \mu \mathrm{g}$ glycogen. Total RNA (20 ng) was converted into cDNA in $20 \mu \mathrm{l}$ using the Omniscript reverse transcriptase (Qiagen). For each target mRNA, $0.5 \mu \mathrm{l}$ cDNA $(0.05 \mu \mathrm{l}$ for $M y o D$ and beta-actin) was amplified in a $25 \mu 1$ SYBR Green PCR reaction containing $1 \times$ Quantitect master mix (Qiagen) and $100 \mathrm{nM}$ of each primer. The amplification was monitored real-time using the MX3000P Real-time PCR machine (Stratagene). The $\mathrm{C}_{t}$ values were related to a standard curve made with the cloned PCR products or with cDNA dilutions. The quantities were normalized to total RNA (cDNA per ng RNA). For visualization, after PCR to 50 cycles the PCR products were run in 3\% agarose gels containing Gelstar (Cambrex). RNA from primary muscle cells, the brain of adult or newborn mice, and 7-day embryos were used as positive controls. The following gene expression assays were performed: Pax3, Pax7, MyoD, Myf5, myogenin, nestin,
Sox10, GFAP, beta-III tubulin, beta-actin, MAP2, MBP, NG2 and Oct-4. Detailed information for primers is shown in the table below.

\section{Table 1. Primers}

\begin{tabular}{ll}
\hline Name & Oligo Sequence \\
\hline Mouse Tubulin-b3 SybrS & TTCGTCTCTAGCCGCGTGAAGT \\
Mouse Tubulin-b3 SybrA & CATCGCTGATGACCTCCCAGAA \\
Mouse Sox10 SybrS & ACCACCGGCACCCAGAAGAAG \\
Mouse Sox10 SybrA & TGGGGTGGTTGGAGGGGTTG \\
Mouse Pax7 SybrS & TGGCACAGAGGACCAAGCTCAC \\
Mouse Pax7 SybrA & CCCGGCAGAAGGTGGTTGAAG \\
Mouse Pax3 SybrS & ACAGACAGCTTTGTGCCTCCATC \\
Mouse Pax3 SybrA & CGTGGTTGGTCAGAAGTCCCATT \\
Mouse NG2 SybrS & CCAGCCGTCTCTGGAAGAACAAAG \\
Mouse NG2 SybrA & TAGGAGGTTGGCGGCATCAAGG \\
Mouse Nestin SybrS & GCAGCAACTGGCACACCTCAA \\
Mouse Nestin SybrA & CGAGAGTTCTCAGCCTCCAGCA \\
Mouse Myogenin SybrS & CAACTCCCACAGCGCCTCCT \\
Mouse Myogenin SybrA & GTAGGGTCAGCCGCGAGCAA \\
Mouse MyoD SybrS & CGGCAGAATGGCTACGACACC \\
Mouse MyoD SybrA & GCTCGACACAGCCGCACTCTT \\
Mouse myf5 SybrS & CCCGAAAGAACAGCAGCTTTGAC \\
Mouse myf5 SybrA & GACAAGCAATCCAAGCTGGACAC \\
Mouse MBP SybrS & ACGGCCGGACCCAAGATGAA \\
Mouse MBP SybrA & CCCTTGGGATGGAGGTGGTG \\
Mouse MAP2 SybrS & TAATCTGCCACCTTCGCCACCA \\
Mouse MAP2 SybrA & GGAGCCTGAGCCAAGTCACCAC \\
Mouse GFAP SybrS & GGTTGAATCGCTGGAGGAGGAG \\
Mouse GFAP SybrA & CCACGTGGACCTGCTGTTGG \\
Mouse bActin SybrS & TGCTGACAGGATGCAGAAGGAGA \\
Mouse bActin SybrA & CAGAGTACTTGCGCTCAGGAGGA \\
Mouse Oct-4 SybrS & CGAAGCCCTCCCTACAGCAGA \\
Mouse Oct-4 SybrA & GGCGCCGGTTACAGAACCATAC \\
\hline & \\
\hline
\end{tabular}

\section{In Situ Hybridization}

For the detection of the Y-chromosome in NEMP-c1grafted muscles, a mouse chromosome $\mathrm{Y}$ probe (IDMB1055, ID Labs Inc) was used. FISH analysis was carried out according to the manufacturer's instructions, and immunofluorescent staining with neurofilament and GFAP was performed prior to in site hybridization. Sections were fixed in acetone/methanol $(1: 1)$ for $10 \mathrm{~min}$ at $-20^{\circ} \mathrm{C}$, and blocked in 1\% BSA for $30 \mathrm{~min}$ at room temperature. Sections were then incubated with rabbit anti-neurofilament (1:400, Life Technologies) or rabbit anti-GFAP antibody (1:200, Sigma-Aldrich) for $90 \mathrm{~min}$, FITC-labeled sheep anti-rabbit IgG (1:200, Sigma-Aldrich) for $60 \mathrm{~min}$.

\section{Acknowledgments}

We wish to express our sincere gratitude to Professor Bengt Saltin for all his support to the project, Drs. Jennifer E. Morgan and Peter Schjerling for technical support and helpful discussion, Professor Bente K. Pedersen and Dr. Thorkil Ploug for use of their laboratory equipment, and Maiken Christensen, Christina B. Sørensen and K. Skou for technical assistance. This work was supported by the Danish Medical Research Council grant (22-03-0622), the Lundbeck 
Foundation, Vilhelm Pedersens Mindelegat, the Novo Nordisk Foundation, the Copenhagen Muscle Research Center, the Copenhagen Hospital Community Foundation, and the University of Copenhagen. The authors have no conflicting financial interests.

\section{References}

[1] Weissman, I. L. (2000). Stem cells: units of development, units of regeneration, and units in evolution. Cell 100, 157168.

[2] Fuchs, E., and Segre, J. A. (2000). Stem cells: a new lease on life. Cell 100, 143-155.

[3] Sell, S. (2004). Stem cell handbook. (Humana Press, Totowa).

[4] Salero, E., Blenkinsop, T. A., Corneo, B., Harris, A., Rabin, D., Stern, J. H., and Temple, S. (2012). Adult human RPE can be activated into a multipotent stem cell that produces mesenchymal derivatives. Cell Stem Cell 10, 88-95.

[5] Gussoni, E., Soneoka, Y., Strickland, C. D., Buzney, E. A., Khan, M. K., Flint, A. F., Kunkel, L. M., and Mulligan, R. C. (1999). Dystrophin expression in the mdx mouse restored by stem cell transplantation. Nature 401, 390-394.

[6] Qu-Petersen, Z., Deasy, B., Jankowski, R., Ikezawa, M., Cummins, J., Pruchnic, R., Mytinger, J., Cao, B., Gates, C., Wernig, A., et al. (2002). Identification of a novel population of muscle stem cells in mice: potential for muscle regeneration. J. Cell Biol. 157, 851-864.

[7] Corbel, S. Y., Lee, A., Yi, L., Duenas, J., Brazelton, T. R., Blau, H. M., and Rossi, F. M. (2003). Contribution of hematopoietic stem cells to skeletal muscle. Nat. Med. 9, $1528-1532$.

[8] Dezawa, M., Ishikawa, H., Itokazu, Y., Yoshihara, T., Hoshino, M., Takeda, S., Ide, C., and Nabeshima, Y. (2005). Bone marrow stromal cells generate muscle cells and repair muscle degeneration. Science 309, 314-317.

[9] Sampaolesi, M., Blot, S., D’Antona, G., Granger, N., Tonlorenzi, R., Innocenzi, A., Mognol, P., Thibaud, J. L., Galvez, B. G., Barthelemy, I., et al. (2006). Mesoangioblast stem cells ameliorate muscle function in dystrophic dogs. Nature 444, 574-579.

[10] Zhang, Y., Zhu, Y., Li, Y., Cao, J., Zhang, H., Chen, M., Wang, L., and Zhang, C. (2015). Long-term engraftment of myogenic progenitors from adipose-derived stem cells and muscle regeneration in dystrophic mice. Hum. Mol. Genet. 24, 6029-6040.

[11] Fujita, R., Tamai, K., Aikawa, E., Nimura, K., Ishino, S., Kikuchi, Y., and Kaneda, Y. (2015). Endogenous mesenchymal stromal cells in bone marrow are required to preserve muscle function in mdx mice. Stem Cells 33, 962-975.

[12] Hoffman, E. P., Brown, R. H., and Kunkel, L. M. (1987). Dystrophin: the protein product of the Duchenne Muscular Dystrophy locus. Cell 51,919-928.

[13] Briggs, D., and Morgan, J. E. (2013). Recent progress in satellite cell/myoblast engraftment: relevance for therapy. FEBS J. 280, 4281-4293.
[14] Negroni, E., Gidaro, T., Bigot, A., Butler-Browne, G. S., Mouly, V., and Trollet, C. (2015). Invited review: Stem cells and muscle diseases: advances in cell therapy strategies. Neuropathol. Appl. Neurobiol. 41, 270-287.

[15] Lapidos, K. A., Chen, Y. E., Earley, J. U., Heydemann, A., Huber, J. M., Chien, M., Ma, A., and McNally, E. M. (2004). Transplanted hematopoietic stem cells demonstrate impaired sarcoglycan expression after engraftment into cardiac and skeletal muscle. J. Clin. Invest. 114, 1577-1585.

[16] Montarras, D., Morgan, J., Collins, C., Relaix, F., Zaffran, S., Cumano, A., Partridge, T., and Buckingham, M. (2005). Direct isolation of satellite cells for skeletal muscle regeneration. Science 309, 2064-2067.

[17] Cerletti, M., Jurga, S., Witczak, C. A., Hirshman, M. F., Shadrach, J. L., Goodyear, L. J., and Wagers, A. J. (2008). Highly efficient, functional engraftment of skeletal muscle stem cells in dystrophic muscles. Cell 134, 37-47.

[18] Tanaka, K. K., Hall, J. K., Troy, A. A., Cornelison, D. D., Majka, S. M., and Olwin, B. B. (2009). Syndecan-4-expressing muscle progenitor cells in the SP engraft as satellite cells during muscle regeneration. Cell Stem Cell 4, 217-225.

[19] Gang, E. J., Darabi, R., Bosnakovski, D., Xu, Z., Kamm, K. E., Kyba, M., and Perlingeiro, R. C. (2009). Engraftment of mesenchymal stem cells into dystrophin-deficient mice is not accompanied by functional recovery. Exp. Cell Res. 315, 2624-2636.

[20] Darabi, R., Gehlbach, K., Bachoo, R. M., Kamath, S., Osawa, M., Kamm, K. E., Kyba, M., and Perlingeiro, R. C. (2008). Functional skeletal muscle regeneration from differentiating embryonic stem cells. Nat. Med. 14, 134-143.

[21] Davies, K. E., and Grounds, M. D. (2006). Treating muscular dystrophy with stem cells? Cell 127, 1304-1306.

[22] Partridge, T. (2008) Denominator problems in a muscle stem cell study? Cell 135, 997-998.

[23] Weiss, S. W., and Goldblum, J. R. (2001). Enzinger and Weiss's soft tissue tumors. (Mosby, London).

[24] Hendrix, M. J., Seftor, E. A., Seftor, R. E., Kasemeier-Kulesa, J., Kulesa, P. M., and Postovit, L. M. (2007). Reprogramming metastatic tumour cells with embryonic microenvironments. Nat. Rev. Cancer 7, 246-255.

[25] Richler, C., and Yaffe, D. (1970). The in vitro cultivation and differentiation capacities of myogenic cell lines. Dev. Biol. 23, $1-22$.

[26] Rando, T. A., and Blau, H. M. (1994). Primary mouse myoblast purification, characterization, and transplantation for cell-mediated gene therapy. J. Cell Biol. 125, 1275-1287.

[27] Delaporte, C., Dautreaux, B., and Fardeau, M. (1986). Human myotube differentiation in vitro in different culture conditions. Biol. Cell 57, 17-22.

[28] Lendahl, U., Zimmerman, L. B., and McKay, R. D. (1990). CNS stem cells express a new class of intermediate filament protein. Cell 60, 585-595.

[29] Goulding, M., Lumsden, A., and Paquette, A. J. (1994). Regulation of Pax-3 expression in the dermomyotome and its role in muscle development. Development 120,957-971. 
[30] Murphy, M., and Kardon, G. (2011). Origin of vertebrate limb muscle: the role of progenitor and myoblast populations. Curr. Top Dev. Biol. 96, 1-32.

[31] Buckingham, M., and Relaix, F. (2015). PAX3 and PAX7 as upstream regulators of myogenesis. 44, 115-125.

[32] Plaks, V., Kong, N., and Werb, Z. (2015). The cancer stem cell niche: how essential is the niche in regulating stemness of tumor cells? Cell Stem Cell 16, 225-238.

[33] Bonner, P. H., and Hauschka, S. D. (1974). Clonal analysis of vertebrate myogenesis: I. Early developmental events in the chick limb. Dev. Biol. 37, 317-328.

[34] Stockdale, F. E. (1992). Myogenic cell lineages. Del. Biol. 154, 284-298.

[35] Cho, M., Webster, S. G., and Blau, H. M. (1993). Evidence for myoblast-extrinsic regulation of slow myosin heavy chain expression during muscle fiber formation in embryonic development. J. Cell Biol. 121, 795-810.

[36] Maximow, A. A., and Bloom, W. (1948). A text book of histology. (W.B. Saunders Company, Philadelphia), pp.167171.

[37] Schmalbruch, H. (1976). The morphology of regeneration of skeletal muscles in the rat. Tissue Cell 8, 673-692.

[38] Morgan, J. E., Pagel, C. N., Sherratt, T., and Partridge, T. A. (1993). Long-term persistence and migration of myogenic cells injected into pre-irradiated muscles of $\mathrm{mdx}$ mice. J. Neurol. Sci. 115, 191-200.

[39] Pin, C. L., and Merrifield, P. A. (1997). Developmental potential of rat L6 myoblasts in vivo following injection into regenerating muscles. Dev. Biol. 188, 147-166.

[40] Cornelison, D. D., and Wold, B. J. (1997). Single-cell analysis of regulatory gene expression in quiescent and activated mouse skeletal muscle satellite cells. Dev. Boil. 191, 270-283.

[41] Zhao, P., and Hoffman, E. P. (2004). Embryonic myogenesis pathways in muscle regerenation. Dev. Dyn. 229, 380-392.

[42] Coulton, G. R., Morgan, J. E., Partridge, T. A., and Sloper, J. C. (1988). The mdx mouse skeletal muscle myopathy: I. A histological, morphometric and biochemical investigation. Neuropathol. Appl. Neurobiol. 14, 53-70.

[43] Xu, X., Wilschut, K. J., Kouklis, G., Tian, H., Hesse, R., Garland, C., Sbitany, H., Seth, R., Knott, P. D., Hoffman, W. Y., et al. (2015). Human satellite cell transplantation and regeneration from diverse skeletal muscles. Stem Cell Reports $5,419-434$

[44] Dellavalle, A., Sampaolesi, M., Tonlorenzi, R., Tagliafico, E., Sacchetti, B., Perani, L., Innocenzi, A., Galvez, B. G., Messina, G., Morosetti, R., et al. (2007). Pericytes of human skeletal muscle are myogenic precursors distinct from satellite cells. Nat. Cell Biol. 9, 255-267.

[45] Mitchell, K. J., Pannerec, A., Cadot, B., Parlakian, A., Besson, V., Gomes, E. R., Marazzi, G., and Sassoon, D. A. (2010). Identification and characterization of a non-satellite cell muscle resident progenitor during postnatal development. Nat. Cell Biol. 12, 257-266.
[46] Kostallari, E., Baba-Amer, Y., Alonso-Martin, S., Ngoh, P., Relaix, F., Lafuste, P., and Gherardi, R. K. (2015). Pericytes in the myovascular niche promote post-natal myofiber growth and satellite cell quiescence. Development 124, 1242-1253.

[47] Lepper, C., Conway, S. J., and Fan, C. M. (2009). Adult satellite cells and embryonic muscle progenitors have distinct genetic requirements. Nature 460, 627-631.

[48] Neal, A., Boldrin, L., and Morgan, J. E. (2012). The satellite cell in male and female, developing and adult mouse muscle: distinct stem cells for growth and regeneration. PLoS One 7, e37950.

[49] Seale, P., Sabourin, L. A., Girgis-Gabardo, A., Mansouri, A., Gruss, P., and Rudnicki, M. A. (2000). Pax7 is required for the specification of myogenic satellite cells. Cell 102, 777-786.

[50] Romero-Ramos, M., Vourc'h, P., Young, H. E., Lucas, P. A., Wu, Y., Chivatakarn, O., Zaman, R., Dunkelman, N., el-Kalay, M. A., and Chesselet, M. F. (2002). Neuronal differentiation of stem cells isolated from adult muscle. J. Neurosci. Res. 69, 894-907.

[51] Arsic, N., Mamaeva, D., Lamb, N. J., and Fernandez, A. (2008). Muscle-derived stem cells isolated as non-adherent population give rise to cardiac, skeletal muscle and neural lineages. Exp. Cell Res. 314, 1266-1280.

[52] Chanas-Sacre, G., Rogister, B., Moonen, G., and Leprince, P. (2000). Radial glia phenotype: origin, regulation, and transdifferentiation. J. Neurosci. Res. 61, 357-363.

[53] Boldrin, L., Zammit, P. S., and Morgan, J. E. (2014). Satellite cells from dystrophic muscle retain regenerative capacity. Stem Cell Res. 14, 20-29.

[54] Dubowitz, V. (1985). Muscle biopsy: A practical approach. (Bailliere Tindall, London), pp. 294.

[55] Karpati, G., Carpenter, S., and Prescott, S. (1988). Smallcaliber skeletal muscle fibers do not suffer necrosis in $\mathrm{mdx}$ mouse dystrophy. Muscle Nerve 11, 795-803.

[56] Blau, H. M., Webster, C., and Pavlath, G. K. (1983). Defective myoblasts identified in Duchenne muscular dystrophy. Proc. Natl. Acad. Sci. USA 80, 4856-4860.

[57] Delaporte, C., Dehaupas, M., Fardeau, M. (1984). Comparison between the growth pattern of cell cultures from normal and Duchenne dystrophy muscle. J. Neurol. Sci. 64, 149-160.

[58] Maier, F., and Bornemann, A. (1999). Comparison of the muscle fiber diameter and satellite cell frequency in human muscle biopsies. Muscle Nerve 22, 578-583.

[59] Yokota, T., Lu, Q. L., Morgan, J. E., Davies, K. E., Fisher, R., Takeda, S., and Partridge, T. A. (2006). Expansion of revertant fibers in dystrophic mdx muscles reflects activity of muscle precursor cells and serves as an index of muscle regeneration. J. Cell Sci. 119, 2679-2687.

[60] Schiaffino, S., Gorza, L., Pitton, G., Saggin, L., Ausoni, S., Sartore, S., and Lømo, T. (1988). Embryonic and neonatal myosin heavy chain in denervated and paralyzed rat skeletal muscle. Dev. Biol. 127, 1-11. 